\title{
SCIENTIFIC REPORTS

\section{A systematic study of hexavalent chromium adsorption and removal from aqueous environments using chemically functionalized amorphous and mesoporous silica nanoparticles}

\author{
Eun-Hye Jang ${ }^{1,3}$, Seung Pil Pack ${ }^{2}$ Il Kim ${ }^{3} \&$ Sungwook Chung ${ }^{1 *}$
}

We report on the synthesis and characterization of highly monodisperse amorphous silica nanoparticles (ASNs) and mesoporous silica nanoparticles (MSNs) with particle sizes of $15-60 \mathrm{~nm}$. We demonstrate adsorption of $\mathrm{Cr}(\mathrm{VI})$ ions on amino-functionalized $\mathrm{ASNs}\left(\mathrm{NH}_{2}-\mathrm{ASNs}\right)$ and $\mathrm{MSNs}\left(\mathrm{NH}_{2}-\mathrm{MSNs}\right)$ and their removal from aqueous environments and show the specific surface area (SSA) of $\mathrm{NH}_{2}-\mathrm{MSN}$ s is four times as larger as that of $\mathrm{NH}_{2}-\mathrm{ASNs}$ and that more than $70 \%$ of the total SSA of $\mathrm{NH}_{2}-\mathrm{MSNs}$ is due to the presence of nanopores. Analyses of $\mathrm{Cr}(\mathrm{VI})$ adsorption kinetics on $\mathrm{NH}_{2}-\mathrm{ASNs}$ and $\mathrm{NH}_{2}-\mathrm{MSNs}$ exhibited relatively rapid adsorption behavior following pseudo-second order kinetics as determined by nonlinear fitting. $\mathrm{NH}_{2}-\mathrm{ASN}$ and $\mathrm{NH}_{2}-\mathrm{MSNs}$ exhibited significantly higher $\mathrm{Cr}(\mathrm{VI})$ adsorption capacities of 34.0 and $42.2 \mathrm{mg} \cdot \mathrm{g}^{-1}$ and removal efficiencies of 61.9 and $76.8 \%$ than those of unfunctionalized ASNs and MSNs, respectively. The Langmuir model resulted in best fits to the adsorption isotherms of $\mathrm{NH}_{2}-$ ASNs and $\mathrm{NH}_{2}-\mathrm{MSNs}$. The adsorption of $\mathrm{Cr}(\mathrm{VI})$ on $\mathrm{NH}_{2}-\mathrm{ASNs}$ and $\mathrm{NH}_{2}-\mathrm{MSNs}$ was an endothermic and spontaneous process according to the thermodynamic analyses of temperature-dependent adsorption isotherms. The removal efficiencies of $\mathrm{NH}_{2}-\mathrm{ASNs}$ and $\mathrm{NH}_{2}-\mathrm{MSNs}$ exhibited a moderate reduction of less than $25 \%$ of the maximum values after five regeneration cycles. Furthermore, $\mathrm{NH}_{2}-\mathrm{MSNs}$ were also found to reduce adsorbed $\mathrm{Cr}(\mathrm{VI})$ into less harmful $\mathrm{Cr}(\mathrm{III})$.

Chromium is used for many purposes in modern industries. For example, it is used to harden steel and make stainless steel, which are essential raw materials in the construction, heavy machinery, automotive, transportation, energy, and medical industries. Chromium is also used extensively in chrome electroplating processes, in paint pigments, and to produce dyes, leather, plastics, and photographs. These industrial activities generate substantial amounts of hazardous wastes containing relatively high concentrations of chromium, which is recognized as one of the most toxic inorganic pollutants due to its mutagenic and carcinogenic effects on biological species ${ }^{1,2}$.

In aqueous environments, chromium generally exists in the trivalent $(\mathrm{Cr}(\mathrm{III}))$ or hexavalent $(\mathrm{Cr}(\mathrm{VI}))$ oxidation states. Ionic species containing $\mathrm{Cr}(\mathrm{VI})$ such as $\mathrm{CrO}_{4}{ }^{2-}$ or $\mathrm{HCrO}_{4}{ }^{-}$are highly soluble and mobile in nature than $\mathrm{Cr}(\mathrm{III})$, and thus, $\mathrm{Cr}(\mathrm{VI})$ containing species pass through cell membranes readily, whereas $\mathrm{Cr}$ (III) species are poorly cell-permeable ${ }^{3}$. In fact, it has been estimated $\mathrm{Cr}(\mathrm{VI})$ is almost $\sim 100$ times more toxic than $\mathrm{Cr}$ (III) in aqueous environments ${ }^{4,5}$. Sequestration strategies targeting the adsorption and reduction of $\mathrm{Cr}(\mathrm{VI})$ to less harmful $\mathrm{Cr}$ (III) attracted considerable research attention because of their obvious advantages over strategies aimed at the separation of $\mathrm{Cr}(\mathrm{VI})^{6}$.

\footnotetext{
${ }^{1}$ School of Chemical and Biomolecular Engineering, Pusan National University, 2 Busandaehak-ro 63beon-gil, Geumjeong-gu, Busan, 46241, South Korea. ${ }^{2}$ Department of Biotechnology and Bioinformatics, Korea University, 2511 Sejong-Ro, Sejong, 30019, South Korea. ${ }^{3}$ Department of Polymer Science and Engineering, Pusan National University, 2 Busandaehak-ro 63beon-gil, Geumjeong-gu, Busan, 46241, South Korea. *email: sungwook.chung@pusan.ac.kr
} 
Methods such as adsorption ${ }^{7-9}$, ion-exchange ${ }^{10,11}$, membrane separation ${ }^{12,13}$, coagulation $^{14}$, chemical precipitation $^{15,16}$, extraction ${ }^{17}$, dialysis ${ }^{18}$, and electrochemical separation ${ }^{19}$ have been shown to be capable of removing heavy metal ions, including hexavalent chromium from wastewater. Of these different methods, adsorption is probably the most effective, economically feasible, environmentally sustainable, and technologically promising processes ${ }^{20}$. Recently, a variety of adsorbents such as activated carbons ${ }^{7,21}$, iron-based metal oxides ${ }^{22}$, metal-organic frameworks ${ }^{23}$, polymeric and biomass-based materials $\mathrm{s}^{9,24,25}$ have been used for Cr(VI) removal. In particular, polymeric materials have been shown to be highly efficient at adsorbing $\mathrm{Cr}(\mathrm{VI})$ and their highly branched structures can be readily functionalized to selectively adsorb and remove different heavy metal ions ${ }^{26,27}$.

Silica and silica-based composite materials are an essential class of adsorbents that have been widely employed due to their unique and adjustable physicochemical characteristics, which include large surface areas and excellent chemical, thermal, and mechanical stabilities ${ }^{27}$. Stöber silica is often used as an adsorbent and generally described as a nonporous, monodisperse, and amorphous silica composed of spherical particles ${ }^{28}$. A variety of methods such as sol-gel, microemulsion, hydrothermal, and flame-based methods have been devised to synthesize silica particles with diameters in the colloidal range ${ }^{29}$. Over the past years, a collection of mesoporous silica, such as SBA- $1^{30}$, SBA- $15^{31}, \mathrm{MCM}-41^{32}$, and MCM- $48^{33}$ have been synthesized and also used as adsorbents that have highly ordered nanoscale pores with a wide range of pore geometries including hexagonal and cubic arrangements with relatively narrow size distributions. Mesoporous silica with uniform and tailorable pore dimensions exhibits unique material properties such as high specific surface areas and excellent thermal and mechanical stabilities, and hence, has been employed in potential applications ${ }^{34}$. These include their use in heavy metal removal from wastewater ${ }^{6}$, indoor air purification ${ }^{35}, \mathrm{CO}_{2}$ capture $^{36}$, pervaporation membranes for the separation of water from ethanol ${ }^{37}$.

Both Stöber and mesoporous silica materials have been chemically functionalized to enhance $\mathrm{Cr}(\mathrm{VI})$ adsorp$\operatorname{tion}^{38,39}$. For example, nitrogen-containing functional groups like aliphatic and aromatic amines have demonstrated to be extremely effective at enhancing $\mathrm{Cr}(\mathrm{VI})$ adsorption ${ }^{27}$. It has been suggested that the adsorption behavior of $\mathrm{Cr}(\mathrm{VI})$ on functionalized silica surfaces depends on parameters such as the number densities and the binding strengths of the donor groups grafted onto adsorbent surfaces ${ }^{40,41}$. However, little is known of the processes involved, such as of the effect of specific functional groups, or of relationships between adsorption efficiencies and adsorbent sizes, shapes, morphologies, pore densities, and specific surface areas and many aspects of the processes have yet to be explored systematically.

Herein, we present the results of work aimed at preparing two types of bare and two types of $\mathrm{NH}_{2}$-functionalized silica nanoparticles of similar sizes, that is, amorphous silica nanoparticles (ASNs) with an amorphous solid core and mesoporous silica nanoparticles (MSNs) with a nanoporous core. Also, we investigated their $\mathrm{Cr}(\mathrm{VI})$ adsorption and removal performances using aqueous batch systems. $\mathrm{N}_{2}$ sorption measurements showed the specific surface areas (SSAs) of unfunctionalized MSNs were twice as large as those of ASNs, and that the SSAs of 3-aminopropyl triethoxysilane (APTES) functionalized MSNs $\left(\mathrm{NH}_{2}-\mathrm{MSNs}\right)$ were four times as large as those of APTES functionalized ASNs ( $\mathrm{NH}_{2}-\mathrm{ASNs}$ ). In addition, we confirmed that $>70 \%$ of the total SSAs of bare and $\mathrm{NH}_{2}$-functionalized MSNs were ascribable to nanopores using a simplified geometric scaling approach. We examined the effect of temperature and $\mathrm{pH}$ on adsorption and removal of $\mathrm{Cr}(\mathrm{VI})$ using bare and $\mathrm{NH}_{2}$-functionalized ASNs and MSNs. We discovered that unfunctionalized ASNs and MSNs had considerably lower adsorption capacities that were less than $\sim 4 \%$ of those of $\mathrm{NH}_{2}-\mathrm{ASNs}$ and $\mathrm{NH}_{2}-\mathrm{MSNs}$. Furthermore, we confirmed that the optimal $\mathrm{pH}$ for reaching maximum $\mathrm{Cr}(\mathrm{VI})$ uptake and removal efficiency were 2.0. Systematic analyses of $\mathrm{Cr}(\mathrm{VI})$ adsorption kinetics using non-linear fitting of a pseudo-second order kinetic model at $\mathrm{pH}$ 2.0 and $25^{\circ} \mathrm{C}$ revealed rapid adsorption of $\mathrm{Cr}(\mathrm{VI})$ on $\mathrm{NH}_{2}-\mathrm{ASNs}$ and $\mathrm{NH}_{2}-\mathrm{MSNs}$ whereby $\sim 90 \%$ of $\mathrm{Cr}$ (VI) was adsorbed within one minute. In-depth analyses of the equilibrium adsorption isotherms of $\mathrm{NH}_{2}-\mathrm{ASNs}$ and $\mathrm{NH}_{2}-\mathrm{MSN}$ revealed that Langmuir model resulted in the best fit to the experimental data. $\mathrm{NH}_{2}-\mathrm{ASNs}$ and $\mathrm{NH}_{2}-\mathrm{MSN}$ s exhibited significantly higher $\mathrm{Cr}(\mathrm{VI})$ adsorption capacities $\left(q_{e}\right)$ of 34.0 and $42.2 \mathrm{mg} \cdot \mathrm{g}^{-1}$ and removal efficiencies $(R)$ of 61.9 and $76.8 \%$ than those of unfunctionalized ASNs and MSNs $\left(0.4\right.$ and $1.3 \mathrm{mg} \cdot \mathrm{g}^{-1}$ and 0.7 and $2.4 \%$ ), respectively. Furthermore, we found that $\mathrm{NH}_{2}$-functionalized ASNs and MSNs could also reduce adsorbed $\mathrm{Cr}(\mathrm{VI})$ to $\mathrm{Cr}(\mathrm{III})$ and that the amount of $\mathrm{Cr}(\mathrm{VI})$ reduction adsorbed on $\mathrm{NH}_{2}-\mathrm{MSN}$ was three times as large as those on $\mathrm{NH}_{2}$-ASNs.

\section{Materials and Methods}

Materials. Tetraethyl orthosilicate (TEOS, $\geq 99 \%$, Aldrich), cetyltrimethyl ammonium chloride (CTAC, 95\%, Wako), triethanolamine (TEA, $\geq 99 \%$, Aldrich), 3-aminopropyl triethoxysilane (APTES, 99\%, Aldrich), potassium dichromate $\left(\mathrm{K}_{2} \mathrm{Cr}_{2} \mathrm{O}_{7}, \geq 99.5 \%\right.$, KANTO), and 1,5-diphenylcarbazide (DPC, special GR grade, SAMCHUN) were purchased and used as supplied. All other chemicals including the solvents used such as toluene, acetone, absolute ethanol, $1 \mathrm{~N}$ sulfuric acid, hydrochloric acid solution (10 $\mathrm{wt} \%)$, and ammonium hydroxide $\left(\mathrm{NH}_{4} \mathrm{OH}\right)$ solution $(25 \mathrm{wt} \%)$ were of analytical ACS regent grade and once purchased, they were used as supplied.

Preparation of monodisperse ASNs. Stöber et al. originally reported the synthesis of ASNs via a base-catalyzed hydrolysis and condensation of TEOS ${ }^{42}$. This method and its modifications have been widely used to synthesize monodisperse ASNs ${ }^{43,44}$. We synthesized ASNs using a modified version of the original method. Typically, $4.43 \mathrm{~mL}$ TEOS was added dropwise to a pre-mixed solution of $1.35 \mathrm{~mL}$ doubly distilled deionized water $(18.2 \mathrm{M} \Omega \cdot \mathrm{cm}), 200 \mathrm{~mL}$ absolute ethanol, and $2.25 \mathrm{~mL} 25 \mathrm{wt} \% \mathrm{NH}_{4} \mathrm{OH}$ solution with stirring at $400 \mathrm{rpm}$. The resulting suspension was immediately stirred for $24 \mathrm{~h}$ at $25^{\circ} \mathrm{C}$ and then dialyzed against $5 \mathrm{~L}$ of doubly distilled deionized water using a dialysis cellulose membrane tubing (pore size of 2.5-5 nm, Sigma Aldrich) to remove ethanol and ammonia from the suspension. The dialysate was refreshed 4 times at $2 \mathrm{~h}$ intervals. Finally, ASNs were precipitated by rotaevaporation for $30 \mathrm{~min}$, filtered through a $0.2 \mu \mathrm{m}$ nylon membrane, washed with an excess of absolute ethanol, and dried in a vacuum oven at $25^{\circ} \mathrm{C}$. 
Preparation of monodisperse MSNs. Bein et al. reported the synthesis of MSNs using TEA as a complexing agent for silicic precursors and CTAC as a templating agent for inner pores within ASNs ${ }^{45}$. We synthesized highly monodisperse MSNs with sizes that closely matched those of as-prepared ASNs prepared in a similar manner ${ }^{46}$. Briefly, $0.5 \mathrm{~g}$ CTAC and $0.06 \mathrm{~g}$ TEA were dissolved in $20 \mathrm{~mL}$ doubly distilled deionized water at $80^{\circ} \mathrm{C}$ with stirring at $700 \mathrm{rpm}$ for $1 \mathrm{~h} .1 .5 \mathrm{~mL}$ of TEOS was then added dropwise at a rate of $1 \mathrm{~mL} / \mathrm{min}$. The resulting suspension was then immediately stirred for $1 \mathrm{~h}$ at $80^{\circ} \mathrm{C}$ and as-synthesized MSNs were precipitated by centrifugation at $12,000 \mathrm{rpm}$ for $15 \mathrm{~min}$, washed with an excess of absolute ethanol to remove residual reactants, and dried in a vacuum oven at $25^{\circ} \mathrm{C}$. Finally, MSNs were calcined at temperatures up to $550^{\circ} \mathrm{C}$ for $4 \mathrm{~h}$ using a heating rate of $10^{\circ} \mathrm{C} \cdot \mathrm{min}^{-1}$ to remove $\mathrm{CTAC}$ from inner pores.

Surface functionalization of ASNs and MSNs with APTES. ASNs and MSNs were functionalized with APTES using a modification of a previously described method ${ }^{6,47}$. Approximately $\sim 1 \mathrm{~g}$ of as-synthesized ASNs or calcined MSNs were reacted with $1 \mathrm{~mL}$ of APTES separately in $100 \mathrm{~mL}$ of toluene at $80^{\circ} \mathrm{C}$ with vigorous stirring overnight. Products were removed by filtration, washed with an excess of absolute ethanol, and doubly distilled deionized water to remove most of the unreacted APTES, and dried in air at $25^{\circ} \mathrm{C}$. Because this washing step was not enough to remove all the unreacted and physisorbed APTES, products were re-immersed in doubly distilled deionized water (at sample/water ratio $1 \mathrm{~g} / \mathrm{L}$ ) with stirring for at least $24 \mathrm{~h}$ at $30^{\circ} \mathrm{C}^{48}$. Finally, products were filtered, washed with an excess of absolute ethanol and doubly distilled deionized water, and dried in a vacuum oven at $25^{\circ} \mathrm{C}$.

Scanning electron microscopy (SEM), transmission electron microscopy (TEM), X-ray powder diffraction (XRD). Sizes and morphologies of ASNs and MSNs were investigated by field emission scanning electron microscopy (FESEM) using a Zeiss Supra 40 FESEM unit at an accelerating voltage of 5 to $10 \mathrm{kV}$ and by transmission electron microscopy (TEM) using a Hitachi H-7600 TEM operating at an accelerating voltage of $80 \mathrm{kV}$. High-resolution TEM (HRTEM) and scanning TEM (STEM) analyses were performed on an FEI TALOS F200X TEM operating at an accelerating voltage of $200 \mathrm{kV}$. The chemical compositions of ASNs and MSNs were analyzed simultaneously using an energy dispersive X-ray spectroscopy (EDS) detector attached to Zeiss Supra 40 FESEM. X-ray powder diffraction (XRD) patterns were produced using a Philips X'Pert-MPD Diffractometer equipped with a monochromatic $X$-ray of $\mathrm{Cu} \mathrm{K}_{\alpha 1}$ radiation $(\lambda=0.15405 \mathrm{~nm})$ at $1.6 \mathrm{~kW}(40 \mathrm{kV}, 30 \mathrm{~mA})$.

Fourier transform infrared spectroscopy (FT-IR) and thermogravimetric analysis/differential thermal analysis (TGA/DTA). ASNs, MSNs, $\mathrm{NH}_{2}-\mathrm{ASNs}$, and $\mathrm{NH}_{2}-\mathrm{MSNs}$ were subjected to Fourier transformation infrared spectroscopy (FT-IR) using a Spectrum GX FT-IR spectrometer and KBr pellet and attenuated total reflection (ATR) techniques. Thermal analyses of $\mathrm{NH}_{2}-\mathrm{ASNs}$ and $\mathrm{NH}_{2}-\mathrm{MSN}$ were carried out using a TA SDT Q600 thermal gravimetric analysis/differential thermal analysis (TGA/DTA) instrument. Typically, $\sim 5 \mathrm{mg}$ of sample was heated in an $\mathrm{Al}_{2} \mathrm{O}_{3}$ crucible at a heating rate of $5^{\circ} \mathrm{C} / \mathrm{min}$ under $\mathrm{N}_{2}$ flow of $100 \mathrm{~mL} / \mathrm{min}$ for up to $750^{\circ} \mathrm{C}$.

X-ray photoelectron spectroscopy (XPS). XPS data of ASNs, MSNs, $\mathrm{NH}_{2}-\mathrm{ASNs}$, and $\mathrm{NH}_{2}-\mathrm{MSNs}$ were acquired using an ESCALAB 250 spectrometer equipped with a monochromatic $\mathrm{X}$-ray source of $\mathrm{Al}$ anode $\mathrm{K}_{\alpha}$ radiation $(1486.6 \mathrm{eV})$ used as an excitation source. Binding energy was calibrated with respect to the $\mathrm{C} 1 \mathrm{~s}$ line of carbon at $284.6 \mathrm{eV}$ before actual measurements.

Nitrogen $\left(\mathrm{N}_{2}\right)$ physisorption experiments for Brunauer-Emmett-Teller (BET) and Barrett-Joyner-Halenda (BJH) analysis. $\mathrm{N}_{2}$ adsorption-desorption measurements were performed on a Quantachrome Autosorb-iQ surface area and pore size analyzer. Samples of ASNs, MSNs, $\mathrm{NH}_{2}-\mathrm{ASNs}$, and $\mathrm{NH}_{2}-$ MSNs were degassed at $300^{\circ} \mathrm{C}$ for $\sim 3$ hours before actual measurements. BET analysis was used to calculate specific surface areas. Pore size distributions were calculated by BJH analysis of the isotherms' desorption branches.

Reagents and standard preparations for UV-Visible spectrophotometric analysis (a.k.a. the DPC method). A standard stock solution of $\mathrm{Cr}(\mathrm{VI})$ was prepared by dissolving $2.829 \mathrm{~g}$ of dried $\mathrm{K}_{2} \mathrm{Cr}_{2} \mathrm{O}_{7}$ in doubly distilled deionized water $(18.2 \mathrm{M} \Omega \mathrm{cm})$ and then diluting further to $1000 \mathrm{~mL}$ and a $100 \mathrm{mg} / \mathrm{L}$ solution of $\mathrm{Cr}(\mathrm{VI})$ was prepared by diluting the standard stock solution. Separately, a 1,5-diphenylcarbazide (DPC) stock solution was prepared by dissolving $50 \mathrm{mg}$ of DPC in $25 \mathrm{~mL}$ of acetone containing $250 \mu \mathrm{L}$ of $1 \mathrm{~N}$ sulfuric acid ${ }^{49,50}$. Working standard $\mathrm{Cr}(\mathrm{VI})$ concentrations of $1,10,20,50$, and $100 \mathrm{mg} / \mathrm{L}$ were prepared from the standard stock solution and their $\mathrm{pH}$ values were adjusted to $\sim 2.0$ with a hydrochloric acid solution (10 wt\%). Then, $3 \mathrm{~mL}$ aliquots from working standard solutions were mixed with $100 \mu \mathrm{L}$ DPC stock solution to form $\mathrm{Cr}(\mathrm{VI})$-DPC complexes, which were quantified by spectrophotometry $\left(\lambda_{\max }=540 \mathrm{~nm}\right)$ at equilibrium. The standard absorbance $v s$. concentration calibration plot was determined by linear regression to have a correlation coefficient $\left(R^{2}\right)$ of 0.9969 and used to determine $\mathrm{Cr}(\mathrm{VI})$ concentrations together with the results from inductive coupled plasma optical emission spectroscopy (ICP OES) before batch and kinetic batch experiments.

Batch and kinetic batch experiments on $\mathrm{Cr}(\mathrm{VI})$ adsorption and removal. $\mathrm{Cr}(\mathrm{VI})$ adsorption and removal experiments were conducted under equilibrium batch conditions. A series of solutions containing predetermined concentrations of $\mathrm{Cr}(\mathrm{VI})$ was prepared by diluting a $100 \mathrm{mg} / \mathrm{L}$ standard stock solution. All experiments were performed in duplicates under ambient conditions at a controlled temperature of $25^{\circ} \mathrm{C}$. Briefly, $4 \mathrm{~mL}$ of $100 \mathrm{mg} / \mathrm{L} \mathrm{Cr}(\mathrm{VI})$ solution $(\mathrm{pH}=2.0$ ) was added to individual $10 \mathrm{~mL}$ volumetric flasks containing $8 \mathrm{mg}$ of ASNs, MSNs, $\mathrm{NH}_{2}-\mathrm{ASNs}$, and $\mathrm{NH}_{2}-\mathrm{MSNs}$. Samples were mixed using a magnetic stirrer at $200 \mathrm{rpm}$ for $\sim 120 \mathrm{~min}$, which was enough to establish adsorption equilibrium. Then, the liquid phase of each solution obtained by filtration through a polytetrafluoroethylene (PTFE-H) membrane of a pore diameter of $0.45 \mu \mathrm{m}$. $\mathrm{Cr}(\mathrm{VI})$ concentrations in 
solutions before and after the batch experiments were measured using the DPC method, and the results were used to calculate the amount of adsorption per used sorbents $\left(q_{t}\right)$ at equilibrium.

The effect of different initial $\mathrm{pH}$ values was investigated in the range of 2.0-7.0 with initial $\mathrm{Cr}(\mathrm{VI})$ concentration of $100 \mathrm{mg} / \mathrm{L}$ at $25^{\circ} \mathrm{C}$. The optimum $\mathrm{pH}$ value for yielding the maximum adsorption capacity was adopted for the remaining experiments. The effect of initial $\mathrm{Cr}(\mathrm{VI})$ concentration was explored in the range of $1-100 \mathrm{mg} / \mathrm{L}$. The adsorption isotherms were measured by varying initial $\mathrm{Cr}(\mathrm{VI})$ concentration from $1-100 \mathrm{mg} / \mathrm{L}$ at four different temperatures of $25,35,45$, and $55^{\circ} \mathrm{C}$ within $2 \mathrm{~h}$, respectively.

Time-dependent adsorption experiments were also conducted under a kinetic batch condition. $\mathrm{NH}_{2}-\mathrm{ASNs}$ or $\mathrm{NH}_{2}-\mathrm{MSNs}$ ( $4 \mathrm{mg}$ of each) were added to a $10 \mathrm{~mL}$ volumetric flask containing a $100 \mathrm{mg} / \mathrm{L} \mathrm{Cr}(\mathrm{VI})$ solution. Samples were then mixed using a magnetic stirrer at $200 \mathrm{rpm}$, and filtrates were obtained after incubation for 1,3 , $5,10,15,30,60$, or $120 \mathrm{~min}$. The $\mathrm{Cr}(\mathrm{VI})$ concentrations in solutions before and after the kinetic batch experiments were measured using the DPC method, and the results were used to calculate $q_{t}$ values.

Adsorption efficiency, (i.e., defined as the amount of $\mathrm{Cr}(\mathrm{VI})$ adsorbed by $\mathrm{ASNs}, \mathrm{MSNs}, \mathrm{NH}_{2}-\mathrm{ASNs}$, and $\mathrm{NH}_{2}-$ MSNs) and removal efficiency, (i.e., defined as the ability of non-functionalized and $\mathrm{NH}_{2}$-functionalized ASNs and MSNs to reduce $\mathrm{Cr}(\mathrm{VI})$ concentrations) at equilibrium, were calculated in each case using the following mathematical Eqs. 1 and 2

$$
\begin{aligned}
& q_{e}=\frac{\left(C_{0}-C_{e}\right) \times V}{W} \\
& R=\frac{C_{0}-C_{e}}{C_{0}} \times 100
\end{aligned}
$$

where $q_{e}\left(\mathrm{mg} \mathrm{g}^{-1}\right)$ is the adsorption capacity, $R(\%)$ is the maximum $\mathrm{Cr}(\mathrm{VI})$ removal capacity, $C_{0}\left(\mathrm{mg} \mathrm{L}^{-1}\right)$ is the initial concentration of $\mathrm{Cr}(\mathrm{VI}), C_{e}\left(\mathrm{mg} \mathrm{L}^{-1}\right)$ is the equilibrium concentration of $\mathrm{Cr}(\mathrm{VI})$ remained in the solution after the batch experiment, $V(\mathrm{~L})$ is the volume of the solution used in the batch experiment, and $W(\mathrm{~g})$ is the weight of the nanoparticles such as ASNs, MSNs, $\mathrm{NH}_{2}-\mathrm{ASNs}$, and $\mathrm{NH}_{2}-\mathrm{MSNs}$ used as adsorbents in the batch experiments.

Regeneration experiments. Desorption-regeneration experiment was performed 4 times for initial $\mathrm{Cr}(\mathrm{VI})$ concentration of $100 \mathrm{mg} / \mathrm{L}$ at $25^{\circ} \mathrm{C}$ after $\mathrm{Cr}(\mathrm{VI})$ desorption by $0.1 \mathrm{M} \mathrm{HCl}$ solution at temperature and $\mathrm{pH}$ of $25^{\circ} \mathrm{C}$ and 2.0. After desorption, $\mathrm{NH}_{2}-\mathrm{ASNs}$ and $\mathrm{NH}_{2}-\mathrm{MSNs}$ were filtered, dried, and re-dispersed in a $100 \mathrm{~mL}$ $\mathrm{Cr}(\mathrm{V})$ standard solution for $2 \mathrm{~h}$ incubation. The $\mathrm{Cr}(\mathrm{VI})$ concentrations in solutions before and after the incubation were determined using the DPC method. All the experiments were duplicated, and the average values of the measurements were selected for analysis and plotting while the errors of the measurements were kept within 5\%.

Data analysis of adsorption kinetics. If an adsorption rate follows pseudo-second order kinetics with respect to the adsorption sites of sorbents, the appropriate kinetic equation may be expressed as Eq. 3

$$
\frac{d q_{t}}{d t}=k\left(q_{e}-q_{t}\right)^{2}
$$

where $q_{t}$ is the amount adsorbed per sorbents used $\left(\mathrm{mg} \cdot \mathrm{g}^{-1}\right)$ at time $t(\mathrm{~min}), q_{e}$ is the equilibrium adsorption capacity $\left(\mathrm{mg} \cdot \mathrm{g}^{-1}\right)$, and $k$ is the adsorption rate constant $\left(\mathrm{g} \cdot \mathrm{mg}^{-1} \cdot \mathrm{min}^{-1}\right)$. In general, pseudo-second order kinetics describes the kinetics of a system in which the concentration of one reactant is essentially constant, because it is present in excess, and thus, its concentration does not affect reaction rate. The reason why Eq. 3 used the term pseudo in our system was that the amount adsorbed on ASNs, MSNs, $\mathrm{NH}_{2}-\mathrm{ASNs}$, and $\mathrm{NH}_{2}-\mathrm{MSNs}$ governed Eq. 3 instead of the concentration of $\mathrm{Cr}(\mathrm{VI})$ in solutions ${ }^{51}$. The adsorption reaction with forward $\left(k_{1}\right)$ and reverse $\left(k_{-1}\right)$ rates corresponding to Eq. 3 may be written as follows

$$
\mathrm{Cr}+2 \mathrm{AS} \rightleftarrows \mathrm{Cr} \cdot \mathrm{AS}_{2}
$$

where AS is a vacant adsorption site on a nanoparticle surface and $\mathrm{Cr} \cdot \mathrm{AS}_{2}$ represents a $\mathrm{Cr}(\mathrm{VI})$ ion adsorbed at two sites. Given the assumption that the adsorption process is not limited by diffusion and Eq. 4 is an elementary step, the corresponding rate of the above reaction is expressed as;

$$
\frac{d C_{\mathrm{Cr} \cdot \mathrm{AS}_{2}}}{d t}=k_{1} C_{\mathrm{Cr}} C_{\mathrm{AS}}^{2}-k_{-1} C_{\mathrm{Cr} \cdot \mathrm{AS}_{2}}
$$

where $C_{i}$ represents to the concentration of species $i$ at time $t, k_{1}$ is the forward reaction rate, and $k_{-1}$ is the reverse reaction rate. Two additional assumptions are made to simplify Eq. 5 to 3. First, as adsorption is an irreversible process, the rate of desorption, $\left(k_{-1} C_{\mathrm{Cr} \cdot \mathrm{AS}}\right)$, is relatively insignificant and can be neglected. Second, the concentration of $\mathrm{Cr}(\mathrm{VI})$ in solutions $\left(C_{\mathrm{Cr}}\right)$ remains almost constant during the adsorption process ${ }^{52}$. Based on these assumptions, the concentrations of adsorbed species $\left(C_{\mathrm{Cr} \cdot \mathrm{AS}_{2}}\right)$ and vacant sites to the amounts adsorbed $\left(C_{\mathrm{AS}}\right)$ at time $t$ and at equilibrium are proportional to $q_{t}$ and $q_{e}-q_{t}$, respectively.

$$
\begin{gathered}
C_{\mathrm{Cr} \cdot \mathrm{AS}_{2}} \propto q_{t} \\
C_{\mathrm{AS}} \propto\left(q_{e}-q_{t}\right)
\end{gathered}
$$




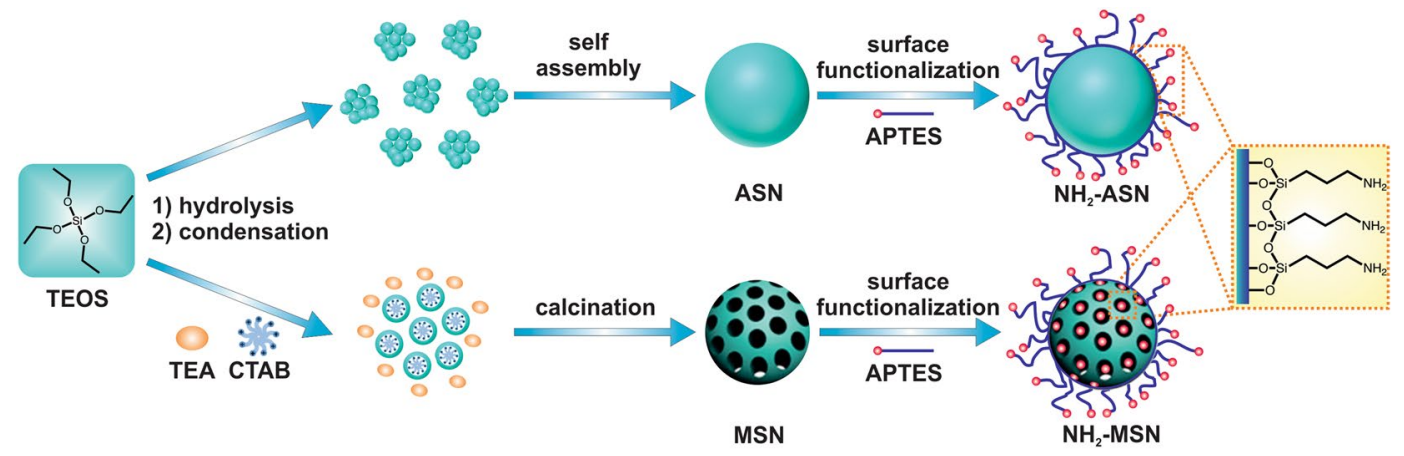

Figure 1. Schematic diagram of the preparation of amorphous silica nanoparticle (ASN), mesoporous silica nanoparticle (MSN), and aminopropyl-functionalized ASN and MSN.

Applying Eqs. 6 and 7 to Eq. 5 and subsequent integration of Eq. 5 and applying the initial condition of $q_{t}=0$ at $t=0$ resulted in a non-linear equation for $q_{t}$ as a function of $t$.

$$
q_{t}(t)=\frac{q_{e}^{2} k_{2} t}{1+q_{e} k_{2} t}
$$

where $k_{2}$ is the pseudo-second order adsorption rate constant $\left(\mathrm{g} \cdot \mathrm{mg}^{-1} \cdot \mathrm{min}^{-1}\right), q_{t}$ is the adsorption capacity $\left(\mathrm{mg}^{-1} \mathrm{~g}^{-1}\right.$, i.e., the amount of $\mathrm{Cr}(\mathrm{VI})$ adsorbed per mass of nanoparticles used at time $t$, and $q_{e}$ is adsorption capacity $\left(\mathrm{mg}^{-1}\right)$ at equilibrium.

A linearized form of Eq. 8 has often been used to obtain adsorption kinetics parameters using linear regression, which has been most widely used to analyze pseudo-order adsorption kinetics ${ }^{51,53-55}$.

$$
\frac{t}{q_{t}(t)}=\frac{1}{k_{2} q_{e}^{2}}+\frac{t}{q_{e}}
$$

Best fits to the adsorption data shown in Fig. 8A were obtained using both linear and non-linear regression using Eqs. 8 and 9, respectively. Plots of standardized residuals of the above best fits were obtained in order to assess the quality of the good fit (Fig. S5). Standardized residuals were calculated using the following expression

$$
\text { standard residual }(\mathrm{SR})=\frac{q_{t}-q_{t}^{f i t}}{s d}
$$

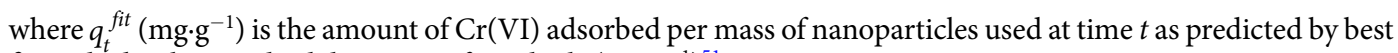
fit, and $s d$ is the standard deviation of residuals $\left(\mathrm{mg}^{-\mathrm{g}^{-1}}\right)^{51}$.

The intraparticle diffusion kinetics, as described by the Weber-Morris model, may be expressed with the following expression

$$
q_{t}(t)=k_{d i} t^{\frac{1}{2}}+C_{i}
$$

where $K_{d i}\left(\mathrm{~g} \cdot \mathrm{mg}^{-1} \cdot \mathrm{min}^{1 / 2}\right)$ is the rate parameter during stage $i$, which is calculated from the slope of the plot of $q^{t}$ versus $t^{1 / 2}$, and $C_{i}$ is the intercept during stage $i$, which provides information about the thickness of the boundary layer ${ }^{56,57}$. Best fits to the adsorption data shown in Fig. 8B were obtained by linear regression using Eq. 11.

\section{Results and Discussion}

Structural analysis of ASNs and MSNs. We used a method reported by Stöber and others ${ }^{42-44}$ to prepare amorphous silica nanoparticles (ASNs) of various sizes ranging from $\sim 15$ and $\sim 60 \mathrm{~nm}$. By using triethanolamine (TEA) and cetyltrimethylammonium chloride (CTAC) as surfactants to form sacrificial micelles, which templated pores within ASNs, we were able to produce mesoporous silica nanoparticles (MSNs) with nanoscale mesopores (a.k.a. nanopores) using a modified Stöber method ${ }^{46}$. Figure 1 illustrates a schematic diagram of their preparation. Figure 2 shows TEM micrographs of as-synthesized ASNs and MSNs with a relatively narrow size distribution $(<\sim 10 \%)$. Annular dark-field scanning TEM (ADF-STEM) measurements of MSNs revealed a substantial contrast differentiation within the MSNs, which we attributed the difference of electron densities caused by the presence of nanopores (inset in Fig. 2B). These results suggest that nanopores of approximately sub-8nm diameter were present within MSNs but did not provide detailed information about the precise sizes, shapes, nor connectivities of the pores.

FT-IR analysis of $\mathbf{N H}_{2}-\mathrm{ASN}$ and $\mathbf{N H}_{2}-\mathbf{M S N s}$. The ASNs and MSNs prepared were reacted with 3 -aminopropyl triethoxysilane (APTES) to introduce surface amino $\left(\mathrm{NH}_{2}-\right)$ groups immediately after their syntheses. Figure 3 shows FT-IR spectra of ASNs (magenta curve) and MSNs (red curve) before APTES functionalization exhibiting the following IR bands of silica moiety at $\sim 3480 \mathrm{~cm}^{-1}(\mathrm{Si}-\mathrm{OH}), \sim 1100-1000 \mathrm{~cm}^{-1}(\mathrm{Si}-\mathrm{O}-\mathrm{Si})$, 


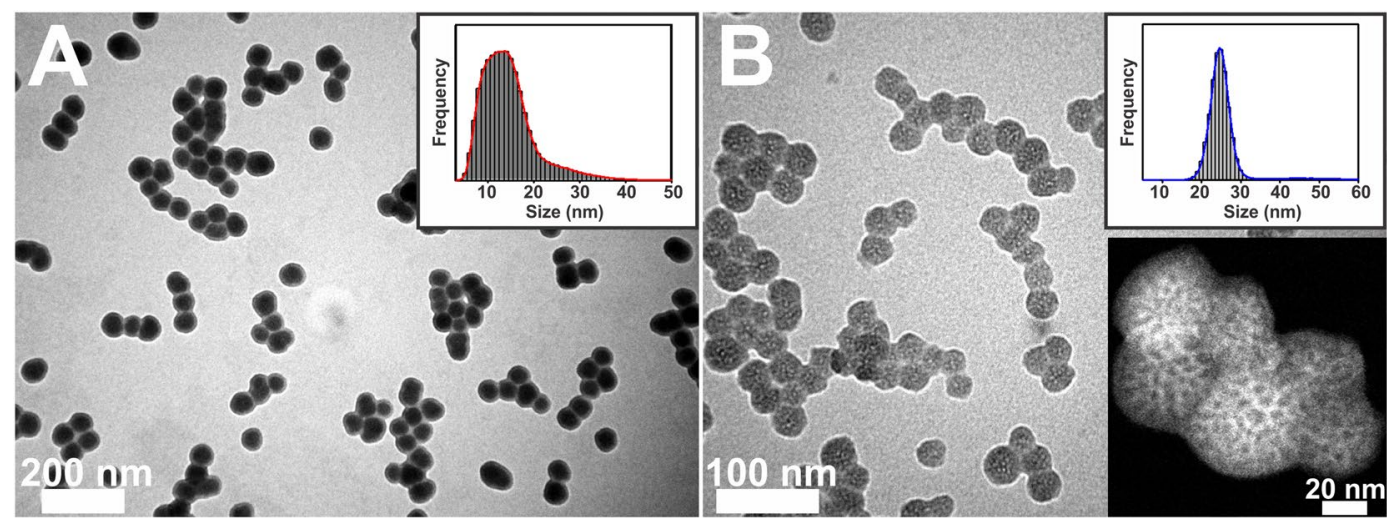

Figure 2. TEM micrographs of (A) ASNs and (B) MSNs. Inset images (upper right) showing histograms of measured particle sizes. The inset in (B) (lower right) shows an annular dark-field scanning transmission microscopy (ADF-STEM) image of MSNs, which show contrast differences due to the existence of intraparticle nanopores.

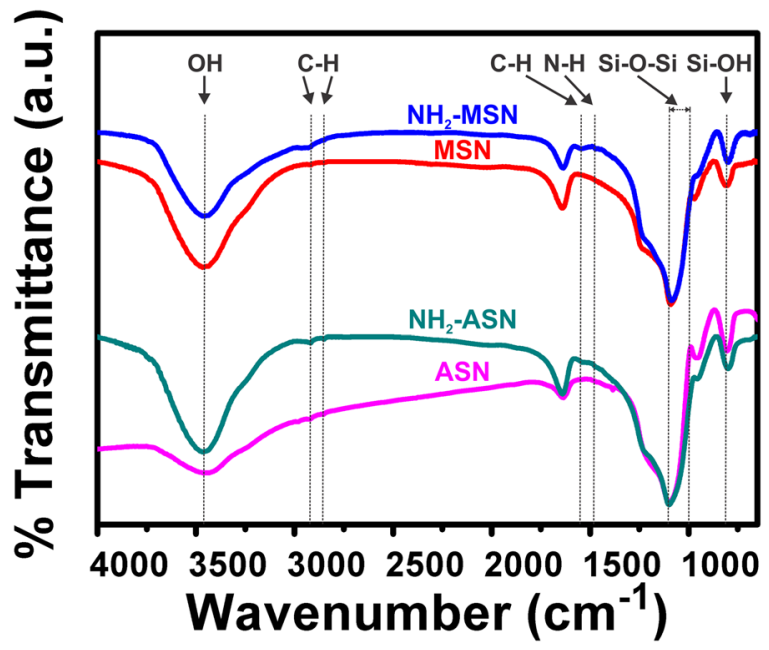

Figure 3. FT-IR spectra of ASNs (magenta), $\mathrm{NH}_{2}-\mathrm{ASNs}$ (dark cyan), MSNs (red), and $\mathrm{NH}_{2}-\mathrm{MSNs}$ (blue). The dotted lines indicate the characteristic IR bands of particular vibrational modes.

and $\sim 920 \mathrm{~cm}^{-1}(\mathrm{Si}-\mathrm{OH})$, which were consistent with values previously reported for silica nanoparticles synthesized by the Stöber method ${ }^{58,59}$. FT-IR spectra of $\mathrm{NH}_{2}$-functionalized ASNs $\left(\mathrm{NH}_{2}-\mathrm{ASNs}\right)$ and $\mathrm{MSNs}\left(\mathrm{NH}_{2}-\right.$ MSNs) contained IR bands at $\sim 2846-2932 \mathrm{~cm}^{-1}$ and $\sim 1459 \mathrm{~cm}^{-1}$ (dark cyan and blue curve) that were assigned to the $\nu(\mathrm{C}-\mathrm{H})$ stretching and $\delta(\mathrm{C}-\mathrm{H})$ bending modes of the alkyl chain of bound APTES. The weak IR bands at $\sim 1459 \mathrm{~cm}^{-1}$ of $\mathrm{NH}_{2}-\mathrm{ASNs}$ and of $\mathrm{NH}_{2}-\mathrm{MSNs}$ were assigned to the $\delta(\mathrm{N}-\mathrm{H})$ bending mode of the amino group of bound APTES, respectively. These IR bands of the $\mathrm{NH}_{2}-\mathrm{ASN}$ and $\mathrm{NH}_{2}-\mathrm{MSN}$ were also consistent with previously reported values ${ }^{60,61}$.

Specific surface area of non-functionalized and $\mathrm{NH}_{2}$-functionalized ASNs and MSNs. Low temperature $\mathrm{N}_{2}$ adsorption-desorption isotherms of ASNs, MSNs, and $\mathrm{NH}_{2}-\mathrm{ASNs}$ and $\mathrm{NH}_{2}-\mathrm{MSNs}$ were obtained to determine their specific surface areas and porosities. Figure 4 shows $\mathrm{N}_{2}$ sorption isotherms and pore size distributions of ASNs, $\mathrm{NH}_{2}-\mathrm{ASNs}, \mathrm{MSNs}$, and $\mathrm{NH}_{2}-\mathrm{MSN}$. The shapes of all four isotherms were similar to that of the characteristic type IV isotherm described in the IUPAC classification ${ }^{62,63}$. In particular, the isotherms of the ASNs and $\mathrm{NH}_{2}-\mathrm{ASN}$ exhibited distinctive type $\mathrm{H} 2$ hysteresis (IUPAC classification) with an extended loop indicating the existence of disordered pores in the pressure $\left(P / P_{0}\right)$ range between 0.6 and 1 . However, the hysteresis loop of isotherms of MSNs and $\mathrm{NH}_{2}-\mathrm{MSNs}$ was similar to type $\mathrm{H} 1$ hysteresis (IUPAC classification), which is commonly observed for mesoporous silica materials with well-defined cylindrical pores ${ }^{64,65}$ within the same pressure $\left(P / P_{0}\right)$ range. The pore size distributions of ASNs and $\mathrm{NH}_{2}-\mathrm{ASNs}$ (inset plots in Fig. $4 \mathrm{~A}$ ), as determined by the Brunauer-Emmett-Teller (BET) ${ }^{66}$ and Barrett-Joyner-Halenda $(\mathrm{BJH})^{67}$ analysis, showed a major peak corresponding to their most probable size at $\sim 3 \mathrm{~nm}$. On the other hand, the pore size distributions of MSNs and $\mathrm{NH}_{2}-\mathrm{MSNs}$ (inset in Fig. 4B) revealed additional peaks, which suggested the presence of pores of different types slightly larger than $\sim 3 \mathrm{~nm}$. These results suggest that the major peaks observed in the pore size distributions of 

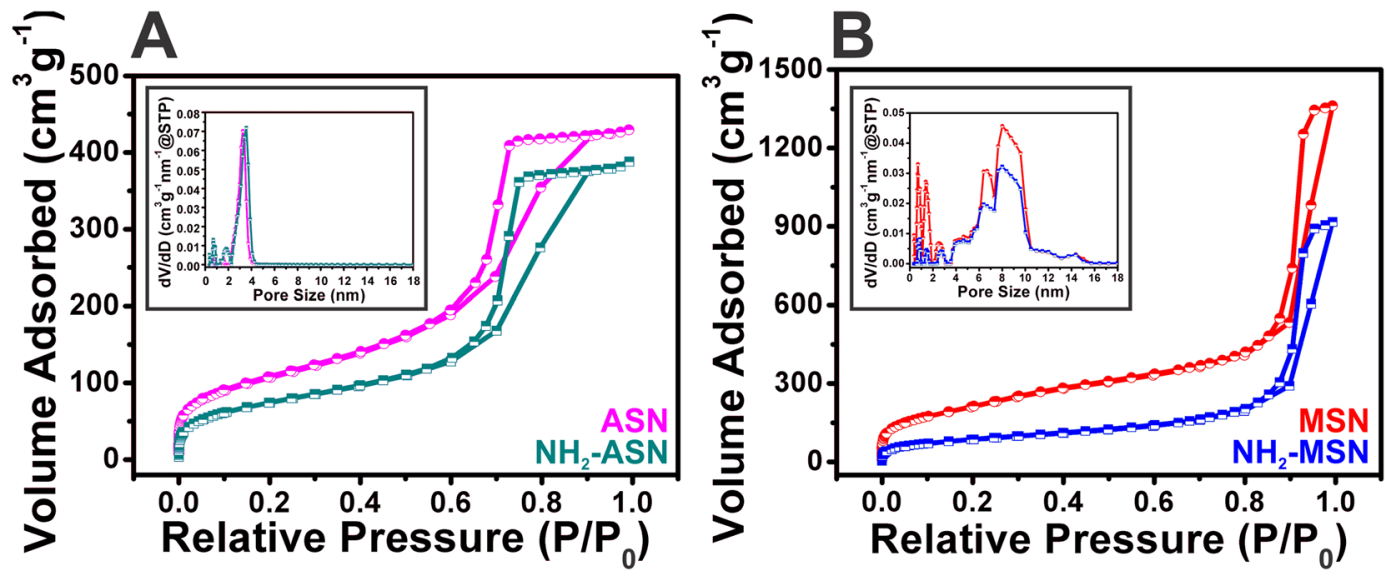

Figure 4. $\mathrm{N}_{2}$ sorption isotherms and pore size distributions of (A) ASNs (magenta) and $\mathrm{NH}_{2}-\mathrm{ASNs}$ (dark cyan) and of (B) MSNs (red) and $\mathrm{NH}_{2}-\mathrm{MSNs}$ (blue). The inset plots show the pore size distribution of (A) ASNs (magenta) and $\mathrm{NH}_{2}-\mathrm{ASNs}$ (dark cyan) and of (B) MSNs (red) and $\mathrm{NH}_{2}-\mathrm{MSNs}$ (blue).
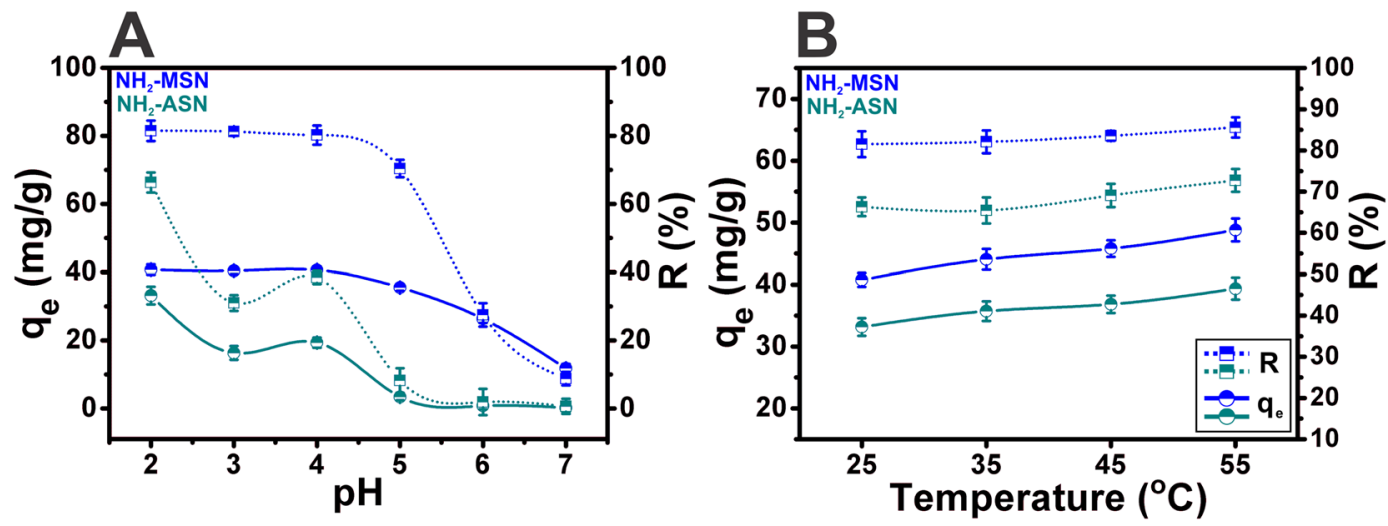

Figure 5. Effect of $\mathrm{pH}$ and temperature on $\mathrm{Cr}(\mathrm{VI})$ adsorption and removal. The adsorption capacity $\left(q_{e}\right)$ and removal efficiency $(R)$ of $\mathrm{NH}_{2}-\mathrm{ASNs}$ and $\mathrm{NH}_{2}-\mathrm{MSNs}$ as a function of solution $\mathrm{pH}$ and temperature.

\begin{tabular}{|l|l|l|l|l|l|l|}
\hline Material & $\begin{array}{l}\text { Particle } \\
\text { diameter }(\mathbf{n m})^{\mathbf{a}}\end{array}$ & $\begin{array}{l}\text { Specific surface } \\
\mathbf{a r e a}\left(\mathbf{m}^{2} \mathbf{g}^{-1}\right)^{\mathbf{b}}\end{array}$ & $\begin{array}{l}\text { Specific surface } \\
\mathbf{a r e a}\left(\mathbf{m}^{\mathbf{2}} \mathbf{g}^{-1}\right)^{\mathbf{c}}\end{array}$ & $\begin{array}{l}\text { Pore volume } \\
\left(\mathbf{c m}^{3} \mathbf{g}^{-1}\right)^{\mathbf{c}}\end{array}$ & $\begin{array}{l}\text { Pore diameter } \\
(\mathbf{n m})^{\mathbf{c}}\end{array}$ & $\begin{array}{l}\text { Functional group } \\
\mathbf{l o a d i n g}\left(\mathbf{m m o l} \mathbf{g}^{-1}\right)^{\mathbf{d}}\end{array}$ \\
\hline ASN & $15 \pm 1$ & 387.0 & 281.9 & 0.66 & 3.43 & - \\
\hline $\mathrm{NH}_{2}-$ ASN & $15 \pm 1$ & 272.9 & 189.9 & 0.60 & 4.40 & 0.25 \\
\hline $\mathrm{MSN}$ & $26 \pm 2$ & 792.1 & 517.4 & 2.11 & 5.32 & - \\
\hline $\mathrm{NH}_{2}-\mathrm{MSN}$ & $26 \pm 2$ & 517.4 & 213.5 & 1.42 & 8.94 & 0.81 \\
\hline
\end{tabular}

Table 1. Sizes, specific surface areas $\left(S_{B E T}\right)$, pore volumes, pore sizes, and functional group loadings of ASNs, $\mathrm{NH}_{2}-\mathrm{ASN}$, MSNs, and $\mathrm{NH}_{2}-\mathrm{MSN}$ as determined by TEM ${ }^{\mathrm{a}}$ measurements, $\mathrm{N}_{2}$ sorption isotherms $\left(\mathrm{BET}^{\mathrm{b}}\right.$ and $\mathrm{BJH}^{\mathrm{c}}$ models), and TGA/DTA ${ }^{\mathrm{d}}$ measurements.

MSNs and $\mathrm{NH}_{2}-\mathrm{MSN}$ were probably caused by void interstices formed by the external surfaces of the aggregated nanoparticles and that the additional peaks observed in those of MSNs and $\mathrm{NH}_{2}-\mathrm{MSNs}$ were caused by disordered nanopores within the nanoparticles.

The specific surface areas $\left(S_{B E T}\right)$ and pore sizes of ASNs, MSNs, $\mathrm{NH}_{2}-\mathrm{ASNs}$, and $\mathrm{NH}_{2}-\mathrm{MSNs}$ were determined from their low temperature $\mathrm{N}_{2}$ adsorption-desorption isotherms using the BET and BJH models. Table 1 summarizes the results. Measured specific surface areas of ASNs, $\mathrm{NH}_{2}-\mathrm{ASNs}$, MSNs, and $\mathrm{NH}_{2}-\mathrm{MSNs}$ were 387.0, 272.9, 792.1 , and $517.4 \mathrm{~m}^{2} \cdot \mathrm{g}^{-1}$, respectively. Notably, the specific surface areas of MSNs and $\mathrm{NH}_{2}-\mathrm{MSNs}$ were nearly twice those of ASNs and $\mathrm{NH}_{2}-\mathrm{ASNs}$, which suggested the presence of nanopores.

It has been reported that the hysteresis exhibited by the sorption isotherms of ASNs and $\mathrm{NH}_{2}-\mathrm{ASNs}$ is associated with capillary condensation in porous structures ${ }^{62,68}$. Because ASNs and $\mathrm{NH}_{2}-\mathrm{ASN}$ can be modeled as hard spheres comprised of bulk $\mathrm{SiO}_{2}$, the arrangements of aggregated ASNs and $\mathrm{NH}_{2}-\mathrm{ASN}$ and the interfacial 
gaps between particles also suggest that the hysteresis loop in their isotherms reflects porosity. Therefore, the $S_{B E T}$ values of ASNs and $\mathrm{NH}_{2}-\mathrm{ASN}$ are likely to be the result of contributions, by the geometric surface areas of ASNs and $\mathrm{NH}_{2}-\mathrm{ASNs}$ that are presumed to behave like hard nanospheres, and the surface areas of the porous architecture formed by the aggregations of these nanoparticles. On the other hand, the $S_{B E T}$ values of mesoporous materials are equal to the sum of geometric surface, and micro- and meso-pore surface ${ }^{28,69}$

The geometric specific surface areas $\left(S_{\text {ext }}\right)$ of nonporous spherical silica particles are inversely proportional to their diameter ' $d$ ' as described by the following mathematical expression $12^{28,70}$, where $\rho$ is the density of bulk silica $\left(\mathrm{SiO}_{2}\right)$.

$$
S_{\text {ext }}=\frac{\text { surface area of a particle }}{\text { density } \times \text { volume of a particle }}=\frac{4 \pi(d / 2)^{2}}{\rho_{\mathrm{SiO}_{2}} \times \frac{4}{3} \pi(d / 2)^{3}}=\frac{6}{\rho_{\mathrm{SiO}_{2}} \times d}
$$

Thus, $S_{\text {ext }}$ can be calculated from the $d$ values of the silica nanoparticles as determined by TEM measurements. Based on assumptions made for the case of ASNs and $\mathrm{NH}_{2}-\mathrm{ASNs}$, the $S_{B E T}$ values of ASNs and $\mathrm{NH}_{2}-\mathrm{ASNs}$ were considered to be approximately equal to the sum of $S_{\text {ext }}$ and the surface area contributions of inner pores and resulting porous structures formed by the external surfaces of the aggregated nanoparticles $\left(S_{t}\right)$ according to the following expression 13.

$$
S_{B E T}=S_{t}+S_{\text {ext }}
$$

This approach has proven to be useful for understanding the nature of the specific surface areas of solid powders comprised of aggregated nanoparticles because the walls of their interstices are presumably formed by the external surface of the nanoparticles ${ }^{48}$. In the case of MSNs and $\mathrm{NH}_{2}-\mathrm{MSNs}$, it is reasonable to assume that nanopore specific surface area $\left(S_{n p}\right)$ contributes to $S_{B E T}$, as described by the following expression 14 .

$$
S_{B E T}=S_{t}+S_{e x t}+S_{n p}
$$

In the case of $26 \mathrm{~nm}$ diameter MSNs and $\mathrm{NH}_{2}-\mathrm{MSNs}$, interstitial environments are probably similar to those of comparably sized ASNs and $\mathrm{NH}_{2}-\mathrm{ASNs}$. Therefore, it is reasonable to assume that the $S_{t}$ values of $26 \mathrm{~nm}$ diameter MSNs and $\mathrm{NH}_{2}-\mathrm{MSNs}$ are similar to those of $26 \mathrm{~nm}$ diameter ASNs and $\mathrm{NH}_{2}-\mathrm{ASNs}$, respectively. Size-corrected specific surface areas $\left(S_{B E T}^{\prime}\right)$ of $26 \mathrm{~nm}$ diameter ASNs and $\mathrm{NH}_{2}-\mathrm{ASNs}$ were extrapolated from a plot of $S_{B E T}$ versus ASN size (see Fig. S1) and consequently, the corresponding $S_{t}$ of $26 \mathrm{~nm}$ diameter MSNs and $\mathrm{NH}_{2}-\mathrm{MSN}$ were estimated by the $S_{\text {ext }}$ of $26 \mathrm{~nm}$ diameter MSNs and $\mathrm{NH}_{2}-\mathrm{MSNs}$ from extrapolated $S_{B E T}$ values using the expression 13. In addition, the $S_{n p}$ of $26 \mathrm{~nm}$ diameter MSNs and $\mathrm{NH}_{2}-\mathrm{MSNs}$ were obtained from the expression 14 using the calculated $S_{B E T}^{\prime}$ and $S_{\text {ext }}$ values.

Table $\mathrm{S} 1$ summarizes various specific surface area types of ASNs, $\mathrm{NH}_{2}-\mathrm{ASNs}$, MSNs, and $\mathrm{NH}_{2}-\mathrm{MSNs}$. The $S_{n p}$ values of MSNs and $\mathrm{NH}_{2}-\mathrm{MSNs}$ were 519.0 and $358.4 \mathrm{~m}^{2} \cdot \mathrm{g}^{-1}$, respectively. Comparison of the $S_{n p}$ and $S_{B E T}$ values of MSNs and $\mathrm{NH}_{2}-\mathrm{MSN}$ showed that the surface area contributions due to the presence of the nanopores were $>65 \%$ of the total specific surface area $\left(S_{B E T}\right)$. Accordingly, the geometric scaling approach enabled the different types of specific surface area of MSNs and $\mathrm{NH}_{2}-\mathrm{MSNs}$ to be evaluated, and the results obtained demonstrated the important roles of nanopores play in the adsorption of $\mathrm{Cr}(\mathrm{VI})$.

TGA analysis of ASNs, MSNs, $\mathbf{N H}_{2}-\mathrm{ASNs}$, and $\mathrm{NH}_{2}-\mathrm{MSNs}$. Amounts of amino groups on the surface of $\mathrm{NH}_{2}-\mathrm{ASNs}$ and $\mathrm{NH}_{2}-\mathrm{MSNs}$ were estimated by thermogravimetric analysis/differential thermal analysis (TGA/ DTA). Figure S2 shows TGA/DTA curves of ASNs (magenta curve), $\mathrm{NH}_{2}-\mathrm{ASNs}$ (dark cyan curve), MSNs (red curve), and $\mathrm{NH}_{2}-\mathrm{MSNs}$ (blue curve) showing weight losses as a function of temperature. Based on TGA/DTA measurements, the functional group loading values of $\mathrm{NH}_{2}-\mathrm{ASNs}$ and $\mathrm{NH}_{2}-\mathrm{MSNs}$ were determined to be $\sim 0.25$ and $\sim 0.81 \mathrm{mmol} \cdot \mathrm{g}^{-1}$, respectively. Table S2 summarizes weight losses and functional group loadings of ASNs, $\mathrm{NH}_{2}-\mathrm{ASNs}, \mathrm{MSNs}$, and $\mathrm{NH}_{2}-\mathrm{MSN}$. Note that the functional group loading on $\mathrm{NH}_{2}-\mathrm{MSN}$ was more than three times greater than on $\mathrm{NH}_{2}-\mathrm{ASNs}$, which we attribute the presence of nanopores.

Effects of $\mathrm{pH}$ and temperature on $\mathrm{Cr}(\mathrm{VI})$ adsorption and removal from aqueous solutions using ASNs, MSNs, $\mathrm{NH}_{2}-\mathrm{ASNs}$, and $\mathrm{NH}_{2}-\mathrm{MSNs}$. ASNs and MSNs exhibited an extremely lower $\mathrm{Cr}(\mathrm{VI})$ adsorption (i.e., their adsorption capacity $\left(q_{e}\right)$ obtained using Eq. 1 less than $\sim 4 \%$ of those of $\mathrm{NH}_{2}-\mathrm{ASNs}$, and $\mathrm{NH}_{2}-\mathrm{MSN}$ shown in Table 2 and Fig. $8 \mathrm{~A}$ ), which was considered to be relatively insignificant. Thus, only the $\mathrm{Cr}(\mathrm{VI})$ adsorption and removal of $\mathrm{NH}_{2}-\mathrm{ASNs}$, and $\mathrm{NH}_{2}-\mathrm{MSNs}$ were investigated for most of the batch experiments. Figure 5 shows the effects of $\mathrm{pH}$ and temperature on $\mathrm{Cr}(\mathrm{VI})$ adsorption and removal from aqueous solutions in the $\mathrm{pH}$ and temperature range of $2.0-7.0$ and $25-55^{\circ} \mathrm{C}$, respectively. A few aspects of the results are worth addressing. First, the adsorption capacity $\left(q_{e}\right)$, defined in Eq. 1, of $\mathrm{NH}_{2}-\mathrm{ASN}$ and $\mathrm{NH}_{2}-\mathrm{MSNs}$ increased from 33.2 to 39.4 and 40.8 to $44.8 \mathrm{mg} \cdot \mathrm{g}^{-1}$ while the removal efficiency $(R)$, defined in Eq. 2, slightly increased from 66.3 to 72.7 and 81.5 to $85.6 \%$ with the increasing of temperature, respectively. Although the amounts of increase were not high, they were consistent with the hypothesis that raising the temperature from 25 to $55^{\circ} \mathrm{C}$ marginally favors the adsorption of $\mathrm{Cr}(\mathrm{VI})$. Also, the increases in the adsorption capacity of $\mathrm{NH}_{2}-\mathrm{ASNs}$ and $\mathrm{NH}_{2}-\mathrm{MSNs}_{\text {with }}$ the increasing temperature implied the endothermic nature of the adsorption process. Second, the $q_{e}$ of $\mathrm{NH}_{2}-\mathrm{ASNs}$ and $\mathrm{NH}_{2}-\mathrm{MSNs}$ improved from 0.2 to 33.2 and 11.8 and $40.8 \mathrm{mg} \cdot \mathrm{g}^{-1}$, and the $R$ from 0.6 to 66.3 and 8.8 to $82.2 \%$ significantly by decreasing the $\mathrm{pH}$ of the solution from 7.0 to 2.0 , respectively. Hence, our results indicated that a higher adsorption capacity was obtained at a lower $\mathrm{pH}$.

The effect of $\mathrm{pH}$ can be rationalized by considering the surface charge of the nanoparticle adsorbents and the degree of ionization of $\mathrm{Cr}(\mathrm{VI})$ species. In general, $\mathrm{Cr}(\mathrm{VI})$ ions exist in several anionic forms such as $\mathrm{HCrO}_{4}{ }^{-}$, $\mathrm{CrO}_{4}{ }^{2-}, \mathrm{HCr}_{2} \mathrm{O}_{7}^{-}$, and $\mathrm{Cr}_{2} \mathrm{O}_{7}{ }^{2-}$ in aqueous solution depending on the solution $\mathrm{pH}$ and concentration ${ }^{3}$. $\mathrm{H}_{2} \mathrm{CrO}_{4}$ 


\begin{tabular}{|l|l|l|l|l|}
\hline Material & $\left.\begin{array}{l}\text { Cr(VI) adsorption } \\
\text { efficiency }\end{array} \mathbf{( m g ~ g}^{-1}\right)$ & $\begin{array}{l}\mathbf{C r}(\mathrm{VI}) \text { removal } \\
\text { efficiency }^{\mathbf{b}}(\mathbf{\%})\end{array}$ & $\begin{array}{l}\text { Total Cr removal } \\
\left(\mathbf{m g ~ g}^{-1}\right)\end{array}$ & $\begin{array}{l}\mathbf{C r}(\mathbf{V I}) \text { reduction } \\
\left(\mathbf{m g ~ g}^{-1}\right)\end{array}$ \\
\hline ASN & 0.4 & 0.7 & - & - \\
\hline $\mathrm{MSN}$ & 1.3 & 2.4 & - & - \\
\hline $\mathrm{NH}_{2}-\mathrm{ASN}$ & 34.0 & 61.9 & 32.6 & 11.5 \\
\hline $\mathrm{NH}_{2}-\mathrm{MSN}$ & 42.2 & 76.8 & 39.8 & 34.7 \\
\hline
\end{tabular}

Table 2. Adsorption and removal efficiency parameters of ASNs, $\mathrm{NH}_{2}-\mathrm{ASNs}, \mathrm{MSNs}$, and $\mathrm{NH}_{2}-\mathrm{MSNs}$ as determined by $\mathrm{Cr}(\mathrm{VI})$ adsorption batch experiments. $\mathrm{Cr}(\mathrm{VI})$ adsorption efficiencies ${ }^{\mathrm{a}}$ were obtained from spectrophotometric measurements using the DPC method. Cr(VI) removal efficiencies ${ }^{\mathrm{b}}$ were calculated using Eqs. 1 and 2. Total $\mathrm{Cr}$ removal ${ }^{c}$ was estimated based on the amount of $\mathrm{Cr}(\mathrm{VI})$ and $\mathrm{Cr}(\mathrm{III})$ adsorbed on nanoparticle surfaces. $\mathrm{Cr}(\mathrm{VI})$ reduction ${ }^{\mathrm{d}}$ was estimated by considering the amount of $\mathrm{Cr}$ (III) in aqueous solutions and on the surfaces of nanoparticles.
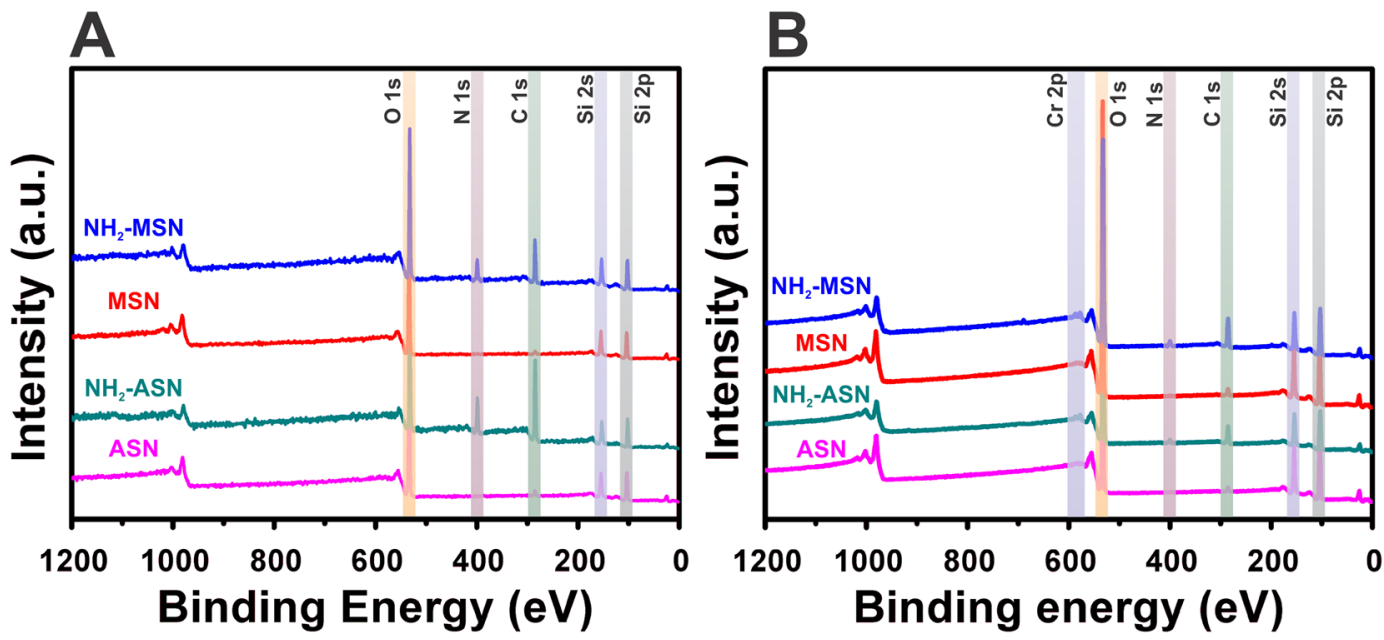

Figure 6. Survey XPS spectra of ASNs (magenta), $\mathrm{NH}_{2}-\mathrm{ASNs}$ (dark cyan), MSNs (red), and $\mathrm{NH}_{2}-\mathrm{MSNs}$ (blue) before (A) and after (B) Cr adsorption. Note the presence of $\mathrm{C} 1 \mathrm{~s}$ and $\mathrm{N}$ 1s peaks in the survey spectra in (A and $\mathbf{B}$ ), which confirmed $\mathrm{NH}_{2}$-functionalization of $\mathrm{ASNs}\left(\mathrm{NH}_{2}-\mathrm{ASNs}\right)$ and $\mathrm{MSNs}\left(\mathrm{NH}_{2}-\mathrm{MSNs}\right)$, and the $\mathrm{Cr} 2 \mathrm{p}$ peaks in $\mathbf{B}$ after $\mathrm{Cr}(\mathrm{VI})$ adsorption.

exists primarily at strong acidic $\mathrm{pH}(<\sim 2)$ and $\mathrm{HCrO}_{4}{ }^{-}$and $\mathrm{Cr}_{2} \mathrm{O}_{7}{ }^{2-}$ are usually detected at $\mathrm{pH}$ range of 2.0-6.0. When the $\mathrm{pH}$ increases to 7.0 and above, $\mathrm{CrO}_{4}{ }^{2-}$ is likely to be the primary ionic species. Considering that the $\mathrm{pK}_{\mathrm{a}}$ of the $\mathrm{NH}_{2}$-groups lies within the $\mathrm{pH}$ range 9-10, the surfaces of $\mathrm{NH}_{2}-\mathrm{ASNs}$ and $\mathrm{NH}_{2}-\mathrm{MSN}$ are likely to be composed of ammonium $\left(\mathrm{NH}_{3}{ }^{+}\right.$) and silanol (-Si-O-H) moieties and confer nanoparticle surfaces a net positive charge under acidic conditions ${ }^{71}$. Figure $\mathrm{S} 3$ shows measurements of $\mathrm{pH}$ at the point of zero charge $\left(\mathrm{pH}_{\mathrm{pzc}}\right)$ on the surface of $\mathrm{NH}_{2}$-functionalized ASNs and MSNs. The values of $\mathrm{pH}_{\mathrm{pzc}}$ of $\mathrm{NH}_{2}-\mathrm{ASNs}$ and $\mathrm{NH}_{2}-\mathrm{MSNs}$ were determined to be 8.5 and 8.4, respectively. These results provide compelling evidence that the surface of $\mathrm{NH}_{2}-\mathrm{ASNs}$ and $\mathrm{NH}_{2}-\mathrm{MSNs}$ is positively charged for $\mathrm{pH}$ below the value of $\mathrm{pH}_{\mathrm{pzc}}$. Since $\mathrm{Cr}(\mathrm{VI})$ species formed under these conditions are likely to be anionic $\mathrm{HCrO}_{4}{ }^{-}$and $\mathrm{Cr}_{2} \mathrm{O}_{7}{ }^{2-}$, these results warrant electrostatic attraction of the anionic $\mathrm{Cr}(\mathrm{VI})$ species. However, with increasing $\mathrm{pH}$, the amount of $\mathrm{NH}_{2}$-groups to be protonated is likely dropped. At the same time, the concentration of hydroxyl $\left(\mathrm{OH}^{-}\right)$ion increased and electrostatically competed against anionic $\mathrm{Cr}(\mathrm{VI})$ species, leading to a decline of $\mathrm{Cr}(\mathrm{VI})$ adsorption and removal efficiency. In summary, a very low solution $\mathrm{pH}$ was required to achieve high protonation of the surface $\mathrm{NH}_{2}$-groups and provide the necessary electrostatic attraction of anionic $\mathrm{Cr}(\mathrm{VI})$ species. Consequently, $\mathrm{pH}=2.0$ was selected as the optimal $\mathrm{pH}$ of $\mathrm{Cr}(\mathrm{VI})$ aqueous solution for the following batch experiments at $25^{\circ} \mathrm{C}$.

$\mathrm{Cr}(\mathrm{VI})$ adsorption and removal efficiency of $\mathrm{ASNs}, \mathrm{MSNs}, \mathrm{NH}_{2}-\mathrm{ASNs}$, and $\mathrm{NH}_{2}-\mathrm{MSNs}$. A series of batch experiments on $\mathrm{Cr}(\mathrm{VI})$ adsorption and removal was carried out at the optimal $\mathrm{pH}$ and temperature of 2.0 and $25^{\circ} \mathrm{C}$, respectively. Table 2 summarizes the adsorption and removal efficiency parameters of ASNs, MSNs, $\mathrm{NH}_{2}-\mathrm{ASNs}$, and $\mathrm{NH}_{2}-\mathrm{MSNs}$ by the $\mathrm{Cr}(\mathrm{VI})$ adsorption batch experiments. Notably, the adsorption efficiencies $\left(q_{e}\right)$ of $\mathrm{NH}_{2}-\mathrm{ASNs}$ and $\mathrm{NH}_{2}-\mathrm{MSNs}$ were $\sim 40$ to 80 times greater than those of ASNs and MSNs, which confirmed the impact of $\mathrm{NH}_{2}$-functionalization on the $\mathrm{Cr}(\mathrm{VI})$ adsorption efficiency ${ }^{27,39}$. Maximum $\mathrm{Cr}(\mathrm{VI})$ removal capacity $(R)$ represents the ability of an adsorbent to remove $\mathrm{Cr}(\mathrm{VI})$ from aqueous environments. The maximum $\mathrm{Cr}(\mathrm{VI})$ removal capacities of $\mathrm{NH}_{2}-\mathrm{ASNs}$ and $\mathrm{NH}_{2}-\mathrm{MSNs}$ were determined to be 61.9 and $76.8 \%$, respectively. These values were comparable or marginally better than those reported for functionalized silica nanoparticles ${ }^{72,73}$, mesoporous silica $^{6,39,48,74-76}$, and other hybrid multifunctional nanoparticles ${ }^{77,78}$ designed for $\mathrm{Cr}(\mathrm{VI})$ removal. Notably, the maximum $\mathrm{Cr}(\mathrm{VI})$ removal capacity of $\mathrm{NH}_{2}-\mathrm{MSNs}$ was $76.8 \%$, which was 1.2 times higher than the $61.9 \%$ of 

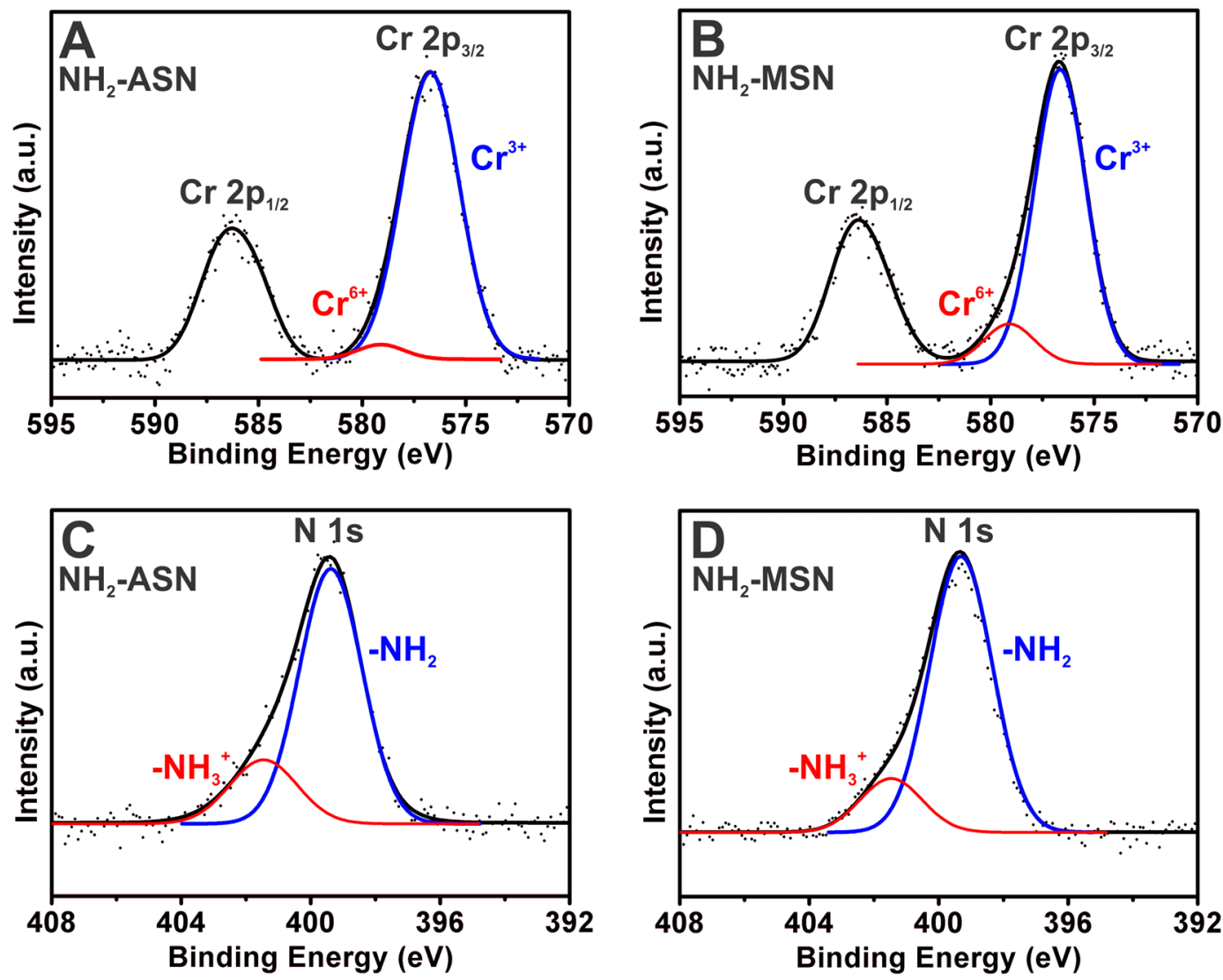

Figure 7. High resolution XPS spectra of $\mathrm{Cr} 2 \mathrm{p}(\mathbf{A}$ and $\mathbf{B})$ and $\mathrm{N} 1 \mathrm{~s}(\mathbf{C}$ and $\mathbf{D})$ of $\mathrm{NH}_{2}-\mathrm{ASNs}$ and $\mathrm{NH}_{2}-\mathrm{MSNs}$ after $\mathrm{Cr}(\mathrm{VI})$ adsorption. Dotted black curves were obtained from XPS measurements, and solid black curves are best fits obtained by Lorentzian-Gaussian deconvolution. Blue and red curves obtained by the deconvolution of (A and $\mathbf{B}$ ) were assigned to $\mathrm{Cr}(\mathrm{III})$ and $\mathrm{Cr}(\mathrm{VI})$, respectively. Blue and red curves of $(\mathbf{C}$ and $\mathbf{D})$ were assigned to neutral $\mathrm{NH}_{2}$ - and cationic $\mathrm{NH}_{3}{ }^{+}$- moieties on the surfaces of $\mathrm{NH}_{2}-\mathrm{ASNs}$ and $\mathrm{NH}_{2}-\mathrm{MSNs}$ after $\mathrm{Cr}(\mathrm{VI})$ adsorption, respectively.

$\mathrm{NH}_{2}$-ASNs. Thus, our results suggest that a combination of a high density of nanopores within silica nanoparticles and high surface coverage by functional amine groups enhance both adsorption and removal efficiencies of $\mathrm{Cr}(\mathrm{VI})$.

XPS analysis of $\mathrm{Cr}(\mathrm{VI})$ adsorption on ASNs, MSNs, $\mathrm{NH}_{2}-\mathrm{ASNs}$, and $\mathrm{NH}_{2}-\mathrm{MSNs}$. Figure 6 shows survey XPS spectra of ASNs, MSNs, $\mathrm{NH}_{2}-\mathrm{ASNs}$, and $\mathrm{NH}_{2}-\mathrm{MSNs}$ before and after $\mathrm{Cr}(\mathrm{VI})$ adsorption. The survey XPS spectra in Fig. 6A, which were obtained over the full energy range confirm the existence of common elements such as $\mathrm{O}$ and Si before $\mathrm{Cr}(\mathrm{VI})$ adsorption. Note that the presence of $\mathrm{C} 1 \mathrm{~s}$ and $\mathrm{N} 1 \mathrm{~s}$ peaks in the spectra of $\mathrm{NH}_{2}-\mathrm{ASN}$ and $\mathrm{NH}_{2}-\mathrm{MSNs}$ in Fig. 6A confirmed the presence of surface $\mathrm{NH}_{2}$ moieties. High resolution XPS scans of $\mathrm{NH}_{2}-\mathrm{ASN}$ and $\mathrm{NH}_{2}-\mathrm{MSN}$ in Fig. $\mathrm{S} 4$ revealed the following binding energies (BEs): a C $1 \mathrm{~s}$ peak at 284.7-284.9 eV, a N 1 s peak at 399.0-399.1 eV, a O 1 s peak at $532.2-532.3 \mathrm{eV}$, and a $\mathrm{Si} 2 \mathrm{p}$ peak at $101.9-102.3 \mathrm{eV}$. Comparison of $\mathrm{O} 1 \mathrm{~s}$ spectra of $\mathrm{NH}_{2}-\mathrm{ASNs}$ and $\mathrm{NH}_{2}-\mathrm{MSN}$ in Fig. S4 shows that their oxygen BEs were similar to those of bound oxygen in bulk silicon di- and sub-oxides, which typically appear at $532.0-533.0 \mathrm{eV}$. It is worth mention that the $\mathrm{Si} 2 \mathrm{p}$ spectra of $\mathrm{NH}_{2}-\mathrm{MSN}$ showed a single peak at $102.3 \mathrm{eV}$, which was marginally higher than that of $\mathrm{NH}_{2}-\mathrm{ASNs}$ at $101.9 \mathrm{eV}$. Considering the fact that the characteristic Si $2 \mathrm{p}$ BE peaks of elementary Si and $\mathrm{SiO}_{2}$ reported in the literature are at 99.5 and $103.5 \mathrm{eV}^{79}$, respectively, our results imply that silicon in the surface layer of $\mathrm{NH}_{2}-\mathrm{ASNs}$ and $\mathrm{NH}_{2}-\mathrm{MSN}$ may exist as intermediate sub-oxide phases $\left(\mathrm{SiO}_{\mathrm{x}}, 0<\mathrm{x} \leq 1\right)$ rather than the fully oxidized $\mathrm{SiO}_{2}{ }^{79,80}$ due to a greater presence of elementary non-oxidized $\mathrm{Si}$ in the surface layers of $\mathrm{NH}_{2}-\mathrm{ASNs}$ and $\mathrm{NH}_{2}-\mathrm{MSNs}$. Furthermore, these values were consistent with those reported for functionalized silica nanoparticles $^{39,81}$, and mesoporous silica ${ }^{6,46}$ systems.

The presence of $\mathrm{Cr} 2 \mathrm{p}$ peaks in the survey XPS spectra of $\mathrm{NH}_{2}-\mathrm{ASNs}$, and $\mathrm{NH}_{2}-\mathrm{MSNs}$ (Fig. 6B) confirmed the surface adsorption of chromium. Figure 7 shows high resolution $\mathrm{Cr} 2 \mathrm{p}$ and $\mathrm{N} 1 \mathrm{~s} \mathrm{XPS}$ spectra of the Cr adsorbed $\mathrm{NH}_{2}-\mathrm{ASNs}$ and $\mathrm{NH}_{2}-\mathrm{MSN}$. The two asymmetric peaks shown in Fig. $7 \mathrm{~A}, \mathrm{~B}$ were assigned to $\mathrm{Cr} 2 \mathrm{p}_{1 / 2}$ and $\mathrm{Cr} 2 \mathrm{p}_{3 / 2}$ orbitals. Deconvolution of the corresponding $\mathrm{Cr} 2 \mathrm{p}_{2 / 3}$ spectra in Fig. 7A,B showed two symmetric peaks that were best fitted by Lorentzian-Gaussian functions. The peak (blue) centered at $\sim 576.7 \mathrm{eV}$ was assigned to $\mathrm{Cr}$ (III) species, while peak (red) centered at $\sim 579.1 \mathrm{eV}$ was attributed to $\mathrm{Cr}(\mathrm{VI})$ based on previously reported values ${ }^{6,82}$. The relative ratios of $\mathrm{Cr}(\mathrm{III})$ to $\mathrm{Cr}(\mathrm{VI})$ on the surface of the $\mathrm{NH}_{2}-\mathrm{ASNs}$ and $\mathrm{NH}_{2}-\mathrm{MSNs}$ (Cr(III)/Cr(VI)) were $\sim 24.7$ and $~ 7.5$, respectively, and were obtained from the areas of the Lorentzian-Gaussian curves (indicated by blue and 

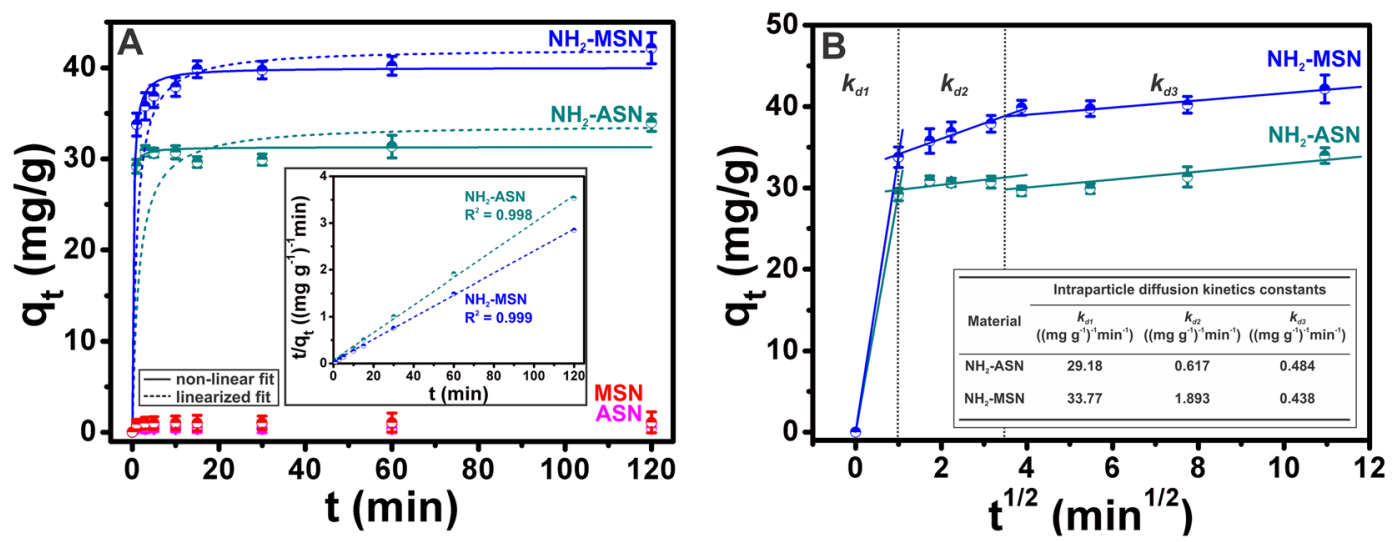

Figure 8. (A) $\mathrm{Cr}(\mathrm{VI})$ adsorption kinetics of ASNs (magenta), MSNs (red), $\mathrm{NH}_{2}-\mathrm{ASNs}$ (dark cyan), and $\mathrm{NH}_{2}-\mathrm{MSNs}$ (blue) as determined by assuming pseudo-second order adsorption kinetics. Best fits to data were successfully obtained using linearized and non-linear fits. (B) $\mathrm{Cr}(\mathrm{VI})$ adsorption kinetics of $\mathrm{NH}_{2}-\mathrm{ASNs}$ and $\mathrm{NH}_{2}-\mathrm{MSNs}$ as determined using the intraparticle diffusion kinetics model. Best fits to data were successfully obtained in time regions, which indicated $\mathrm{Cr}(\mathrm{VI})$ adsorption was a multi-step process.

red curves in Fig. 7). These values imply that most of the Cr adsorbed was in oxidation state III rather than VI. Therefore, the amount of $\mathrm{Cr}(\mathrm{VI})$ reduced to $\mathrm{Cr}(\mathrm{III})$ was estimated from the values in Table 2 . The quantity of total $\mathrm{Cr}$ removal in Table 2 corresponds to the amount of chromium ions, including $\mathrm{Cr}$ (VI) and $\mathrm{Cr}$ (III), eliminated from the solutions after the batch adsorption experiments. They were quantitatively determined by inductively coupled plasma optical emission spectroscopy (ICP OES) in addition to the DPC method. Note that the values of total $\mathrm{Cr}$ removal were smaller than that of $\mathrm{Cr}(\mathrm{VI})$ adsorption capacity in Table 2. We hypothesize that this may be because a significant proportion of adsorbed $\mathrm{Cr}(\mathrm{VI})$ ions was reduced to $\mathrm{Cr}(\mathrm{III})$, and a fraction of adsorbed $\mathrm{Cr}(\mathrm{III})$ ions was released back to the aqueous solutions ${ }^{6}$. Based on the hypothesis, the values of $\mathrm{Cr}(\mathrm{VI})$ reduction in Table 2 were obtained by determining both the amount of $\mathrm{Cr}$ (III) ions in solution and the amount of $\mathrm{Cr}$ (III) adsorbed on the surface of $\mathrm{NH}_{2}-\mathrm{ASNs}$ and $\mathrm{NH}_{2}-\mathrm{MSNs}$ measured by high resolution XPS.

Our high resolution XPS results in Fig. 7, the $\mathrm{pH}_{\mathrm{pzc}}$ vaules, and the results summarized in Table 2 suggest that adsorption is initiated by electrostatic attraction between anionic $\mathrm{Cr}(\mathrm{VI})$ species and surface ammonium groups followed by the reduction of most $\mathrm{Cr}(\mathrm{VI})$ to $\mathrm{Cr}$ (III). Fellenz et al. reported that the $\mathrm{Cr}$ (III) to $\mathrm{Cr}$ (VI) ratio of chromium adsorbed on aminopropyl-functionalized MCM-41 sorbents as determined by XPS was close to 1 after $\mathrm{Cr}(\mathrm{VI})$ adsorption from aqueous environments at $\mathrm{pH} \sim 2.0^{6}$. They also analyzed the XPS spectra of the same samples in the region of $\mathrm{N} 1 \mathrm{~s}$ and determined that $\mathrm{N} 1 \mathrm{~s}$ BEs of $\sim 400.0$ and $\sim 402.0 \mathrm{eV}$ corresponded to cationic ammonium $\left(-\mathrm{NH}_{3}{ }^{+}\right)$and neutral amino $\left(-\mathrm{NH}_{2}\right)$ moieties, respectively, which concurred with previously reported values ${ }^{83}$. Figure 7C,D show deconvoluted $\mathrm{N} 1 \mathrm{~s}$ XPS spectra of $\mathrm{Cr}$ adsorbed $\mathrm{NH}_{2}-\mathrm{ASNs}$ and $\mathrm{NH}_{2}-\mathrm{MSNs}$ were composed of two peaks located at $\sim 399.3$ and $\sim 401.5 \mathrm{eV}$, which were assigned to $-\mathrm{NH}_{3}{ }^{+}$and $-\mathrm{NH}_{2}$ groups, respectively. In the present study, the relative ratios of $-\mathrm{NH}_{2}$ to $-\mathrm{NH}_{3}{ }^{+}$groups on the $\mathrm{Cr}$ adsorbed $\mathrm{NH}_{2}-\mathrm{ASNs}$ and $\mathrm{NH}_{2}-\mathrm{MSN}$ as determined from areas of the Lorentzian-Gaussian curves, were $\sim 3.7$ and $\sim 5.2$, respectively. These values suggest that $-\mathrm{NH}_{2}$ surface coverage was considerably higher than that of $-\mathrm{NH}_{3}{ }^{+}$group coverage, which contradicts expectation because at a pH of $\sim 2.0-\mathrm{NH}_{3}{ }^{+}$groups should predominate ${ }^{71}$. We offer the following explanation for this observation. First, anionic $\mathrm{HCrO}_{4}^{-}$and $\mathrm{Cr}_{2} \mathrm{O}_{7}{ }^{2-}$ species electrostatically interact and bind to surface cationic $-\mathrm{NH}_{3}{ }^{+}$of $\mathrm{NH}_{2}-\mathrm{ASNs}$ and $\mathrm{NH}_{2}-\mathrm{MSNs}$, and subsequently $\mathrm{Cr}$ (VI) is reduced to less toxic $\mathrm{Cr}$ (III), and either $\mathrm{H}^{+}$from $\mathrm{NH}_{3}{ }^{+}$-groups is likely released to medium, or some of adsorbed $\mathrm{Cr}$ (III) are desorbed and released to the aqueous solution to maintain electrostatic charge balance. This explanation is reasonably consistent with the $\mathrm{Cr}(\mathrm{III})$ to $\mathrm{Cr}(\mathrm{VI})$ ratios shown in Fig. 7, although these ratios were slightly higher than previously reported values ${ }^{6,39}$.

$\mathrm{Cr}(\mathrm{VI})$ adsorption kinetics of ASNs, MSNs, $\mathrm{NH}_{2}-\mathrm{ASNs}$, and $\mathrm{NH}_{2}-\mathrm{MSNs}$. The $\mathrm{Cr}(\mathrm{VI})$ adsorption kinetics of ASNs, MSNs, $\mathrm{NH}_{2}-\mathrm{ASNs}$, and $\mathrm{NH}_{2}-\mathrm{MSN}$ are shown in Fig. 8. Figure 8A shows that $>95 \%$ of $\mathrm{Cr}(\mathrm{VI})$ was rapidly adsorbed by $\mathrm{NH}_{2}-\mathrm{ASN}$ and by $\mathrm{NH}_{2}-\mathrm{MSN}$ during the first few minutes of experiments and that the remainder of the $\mathrm{Cr}(\mathrm{VI})$ was adsorbed slowly. The $\mathrm{Cr}(\mathrm{VI})$ adsorption on $\mathrm{NH}_{2}-\mathrm{ASN}$ and $\mathrm{NH}_{2}-\mathrm{MSNs}$ exhibited a saturation behavior when the contact time reached $120 \mathrm{~min}$, which suggests not enough adsorption sites for anionic $\mathrm{Cr}(\mathrm{VI})$ species were available. As more anionic $\mathrm{Cr}(\mathrm{VI})$ species were adsorbed on $\mathrm{NH}_{2}-\mathrm{ASNs}$ and $\mathrm{NH}_{2}-\mathrm{MSN}$, more electrostatic repulsion between negatively charged $\mathrm{Cr}(\mathrm{VI})$ species likely resulted in decreasing the removal efficiency. Although the Cr(VI) adsorption kinetics of ASNs and MSNs were similar to the trend of $\mathrm{NH}_{2}-\mathrm{ASNs}$, and $\mathrm{NH}_{2}-\mathrm{MSNs}$, they exhibited an extremely lower adsorption behavior with their $q_{e}$ values less than $\sim 4 \%$ of those of $\mathrm{NH}_{2}-\mathrm{ASNs}$, and $\mathrm{NH}_{2}-\mathrm{MSNs}$. Because the adsorption capacities of ASNs and MSNs were considered to be relatively insignificant, only the results of $\mathrm{NH}_{2}-\mathrm{ASNs}$, and $\mathrm{NH}_{2}-\mathrm{MSNs}$ were analyzed by obtaining best fit to data using a linearized form of the pseudo-first order model ${ }^{84,85}$, for which $\log \left(q_{e}-q_{t}\right)$ was plotted versus $t$, and a linearized form of the pseudo-second order model ${ }^{86,87}$, for which $q_{t} / t$ was plotted versus $t / q_{e}$. These models are frequently used to describe various adsorption processes involving widely different adsorbents and adsorbates ${ }^{52,88}$. The validity of each model was confirmed using correlation coefficients $\left(R^{2}\right)$ and by checking 


\begin{tabular}{|c|c|c|c|c|c|c|}
\hline \multirow[b]{2}{*}{ Material } & \multirow[b]{2}{*}{$q_{e, e x p}\left(\mathrm{mg} \mathrm{g}^{-1}\right)$} & \multicolumn{3}{|c|}{ Pseudo-2 $2^{\text {nd }}$ order model (linearized fit) ${ }^{\mathrm{a}}$} & \multicolumn{2}{|c|}{ Pseudo-2 $2^{\text {nd }}$ order model (nonlinear fit) } \\
\hline & & $k_{2}\left(\left(\mathrm{mg} \mathrm{g}^{-1}\right)^{-1} \min ^{-1}\right)$ & $q_{e, f i t}\left(\mathrm{mg} \mathrm{g}^{-1}\right)$ & $R^{2}$ & $k_{2}\left(\left(\mathrm{mg} \mathrm{g}^{-1}\right)^{-1} \min ^{-1}\right)$ & $q_{e, f i t}\left(\mathbf{m g ~ g}^{-1}\right)$ \\
\hline $\mathrm{NH}_{2}$-ASN & 33.97 & 0.020 & 33.78 & 0.998 & 0.430 & 31.28 \\
\hline $\mathrm{NH}_{2}-\mathrm{MSN}$ & 42.16 & 0.023 & 41.13 & 0.999 & 0.111 & 40.01 \\
\hline
\end{tabular}

Table 3. Kinetic parameters of $\mathrm{Cr}(\mathrm{VI})$ adsorption on $\mathrm{NH}_{2}-\mathrm{ASN}$ and $\mathrm{NH}_{2}-\mathrm{MSN}$ determined from best fits to the pseudo-second order model shown in Fig. 8A using linearized ${ }^{\mathrm{a}}$ and nonlinear ${ }^{\mathrm{b}}$ fits.

agreement between experimental and fitted value of $q_{e}$. The inset plot in Fig. 8A shows that applying the linearized form of the pseudo-second order model to our data resulted in much higher correlation coefficients $\left(R^{2}>0.99\right)$ than pseudo-first model $\left(R^{2}<0.86\right)$. Surprisingly, corresponding plots with correlation coefficients $\left(R^{2}>0.99\right)$ of the $\mathrm{Cr}(\mathrm{VI})$ adsorption kinetics of $\mathrm{NH}_{2}-\mathrm{ASNs}$ and $\mathrm{NH}_{2}-\mathrm{MSNs}$ (dashed curves in Fig. 8A) did not produce good fits using the linearized fitting process particularly for time between 0 and $20 \mathrm{~min}$. Instead, using nonlinear regression and a pseudo-second order model resulted in much improved fit (solid curves in Fig. 8A) especially for time in the same window. As regards $q_{e}$, reasonably good agreement was also obtained between calculated $\left(q_{e, f i t}\right)$ and experimental $\left(q_{e, \text { exp }}\right)$ values for $\mathrm{NH}_{2}-\mathrm{ASN}$ and $\mathrm{NH}_{2}-\mathrm{MSN}$ using a pseudo-second order model. Table 3 summarizes the kinetic parameters of $\mathrm{Cr}(\mathrm{VI})$ adsorption kinetics on $\mathrm{NH}_{2}-\mathrm{ASNs}$ and $\mathrm{NH}_{2}-\mathrm{MSNs}$ as determined by best fits with the pseudo-second order model using nonlinear regression. It is worth mention that the $q_{e, f i t}$ value of $\mathrm{NH}_{2}-\mathrm{MSNs}$ obtained under equilibrium condition was $40.01 \mathrm{mg} \cdot \mathrm{g}^{-1}$ and this was $\sim 1.3$ times greater than that of $\mathrm{NH}_{2}-\mathrm{ASNs}$. On the other hand, the pseudo-second order rate constant $\left(k_{2}\right)$ of $\mathrm{NH}_{2}-\mathrm{MSNs}$ was $0.111\left(\mathrm{mg} \cdot \mathrm{g}^{-1}\right)^{-1} \cdot \mathrm{min}^{-1}$, which was barely one-fourth of that of $\mathrm{NH}_{2}-\mathrm{ASNs}$.

The reason why the well-accepted linearized form of the pseudo-second order model did not lead to a good fit is unclear. This observation implies that the $\mathrm{Cr}(\mathrm{VI})$ adsorption process might violate one of the important assumptions of the pseudo-second order model, namely that, 1) the adsorption process is irreversible with no desorption, 2) the concentration of $\mathrm{Cr}(\mathrm{VI})$ in medium remains essentially constant, at least during the early adsorption period, and 3 ) the adsorption process is not limited by diffusion ${ }^{52}$. Xiao et al. investigated the reasons why they obtained spuriously high value of correlation coefficients $\left(R^{2} \sim 1\right)$ even when a linearized form of the pseudo-second order model resulted in questionable fits ${ }^{51}$. They concluded that if the pseudo-second order model truly represents experimental data, the nonlinear form should be used instead and that the result be verified using a standardized residual (SR) plot to determine whether residuals are randomly determined and their standard deviations are close to zero ${ }^{51}$. Figure S5 shows that nonlinear fitting delivered the best overall fits with relatively low standardized residuals randomly distributed near zero (i.e., standardized deviations near zero), which was not the case for linearized fitting, and is consistent with a suggestion by Xiao et al. ${ }^{51}$. Therefore, our results show that pseudo-second order adsorption kinetics appropriately describe the adsorption of $\mathrm{Cr}(\mathrm{VI})$ by $\mathrm{NH}_{2}-\mathrm{ASNs}$ and $\mathrm{NH}_{2}-$ MSNs. In addition, our results also suggest that $\mathrm{Cr}(\mathrm{VI})$ adsorption is the result of chemisorption by $\mathrm{NH}_{2}-$ ASNs or $\mathrm{NH}_{2}-\mathrm{MSNs}$ via electrostatic interaction, which is also consistent with our XPS results.

The intraparticle diffusion kinetics based on the Weber-Morris model was used to investigate Cr adsorption process to obtain insight of the mechanism involved. Figure $8 \mathrm{~B}$ shows the adsorption kinetics of $\mathrm{Cr}(\mathrm{VI})$ on $\mathrm{NH}_{2}-$ ASNs and $\mathrm{NH}_{2}-\mathrm{MSNs}$ in three separate time windows and best fits to data resulted in three straight lines for plots of $q_{t}$ versus $t^{1 / 2}$. These linearities imply adsorption probably involves three steps, and the slopes of these plots may determine adsorption rate during these steps. Inset table in Fig. $8 \mathrm{~B}$ presented the values of the rate constant $k_{d 1}$, $k_{d 2}$, and $k_{d 3}$ involving three steps. Several aspects of processes based on the intraparticle diffusion kinetics are worth addressing. First, the $k_{d 1}$ value of $\mathrm{NH}_{2}-\mathrm{MSNs}$ was slightly larger than that of $\mathrm{NH}_{2}-\mathrm{ASNs}$ probably due to their higher specific surface area. However, the rate constant $k_{d 2}$ and $k_{d 3}$ of $\mathrm{NH}_{2}-\mathrm{ASNs}$ and $\mathrm{NH}_{2}-\mathrm{MSNs}$ were not significantly different. Second, a comparison of the rate constants (i.e., $k_{d 1} \gg k_{d 2}>k_{d 3}$ ) revealed that the second and third steps of $\mathrm{Cr}(\mathrm{VI})$ adsorptions on $\mathrm{NH}_{2}-\mathrm{ASNs}$ and $\mathrm{NH}_{2}-\mathrm{MSN}$ were slower than the first and that the rate constants $k_{d 2}$ and $k_{d 3}$ were similar to those obtained by nonlinear fitting using the pseudo-second order model. This analysis suggests the second and third steps were rate-limiting. Third, the results of our analysis based on the intraparticle diffusion kinetics is reasonably consistent with the idea that the concentration of $\mathrm{Cr}(\mathrm{VI})$ in solutions gradually decreased with time without significant desorption of $\mathrm{Cr}(\mathrm{VI})$ from the surface of $\mathrm{NH}_{2}-\mathrm{ASNs}$ and $\mathrm{NH}_{2}-\mathrm{MSN}$. Above all, our analyses show that the intraparticle diffusion kinetic model could interpret the mechanism of adsorption to a reasonable extent.

A few questions remain concerning our analysis of $\mathrm{Cr}(\mathrm{VI})$ adsorption kinetics. First, our results provide limited data of $q_{t}$ within the early time window ( $t \ll 1 \mathrm{~min}$ ) because measuring the amount of $\mathrm{Cr}(\mathrm{VI})$ adsorption after $\leq 1 \mathrm{~min}$ by the DPC methods was difficult and would probably result in unreliable measurements. Therefore, the lower bounds of $k_{d 1}$ rate constants were estimated using best fits with data. Based on these estimates, we concluded that the first step, which was completed within $\leq 1 \mathrm{~min}$, is probably related to the instantaneous adsorption of $\mathrm{Cr}(\mathrm{VI})$ onto the external surfaces of $\mathrm{NH}_{2}-\mathrm{ASNs}$ and $\mathrm{NH}_{2}-\mathrm{MSN}$. Since $\mathrm{Cr}(\mathrm{VI})$ concentration in aqueous environments is relatively high during the initial step, a large concentration gradient may drive the diffusion of $\mathrm{Cr}(\mathrm{VI})$ species to the surfaces of $\mathrm{NH}_{2}-\mathrm{ASNs}$ and $\mathrm{NH}_{2}-\mathrm{MSNs}$. It is worth recalling that the lower bound rate constant $k_{d 1}$ was $\sim 6$ times greater than those of $\mathrm{Cr}(\mathrm{VI})$ physisorption on $\mathrm{Fe}_{3} \mathrm{O}_{4}$ nanoparticles hybridized with carbonaceous materials ${ }^{88}$ and on unfunctionalized mesoporous silica ${ }^{38}$. Though we cannot say definitively that direct comparison between our system and these systems was valid, a sudden increment during the initial step is reminiscent of an enhancement effect by specific functional groups, such as $-\mathrm{NH}_{2}$ or $-\mathrm{NH}_{3}{ }^{+}$groups, which likely accelerate the initial step of $\mathrm{Cr}(\mathrm{VI})$ chemisorption process by lowering the kinetic energy barrier. Second, it may be inadvisable to separate the second and third steps because $k_{d 2}$ and $k_{d 3}$ values were of the same order of magnitude as those obtained by nonlinear fitting using the pseudo-second order model. However, these rate-limiting steps may well 

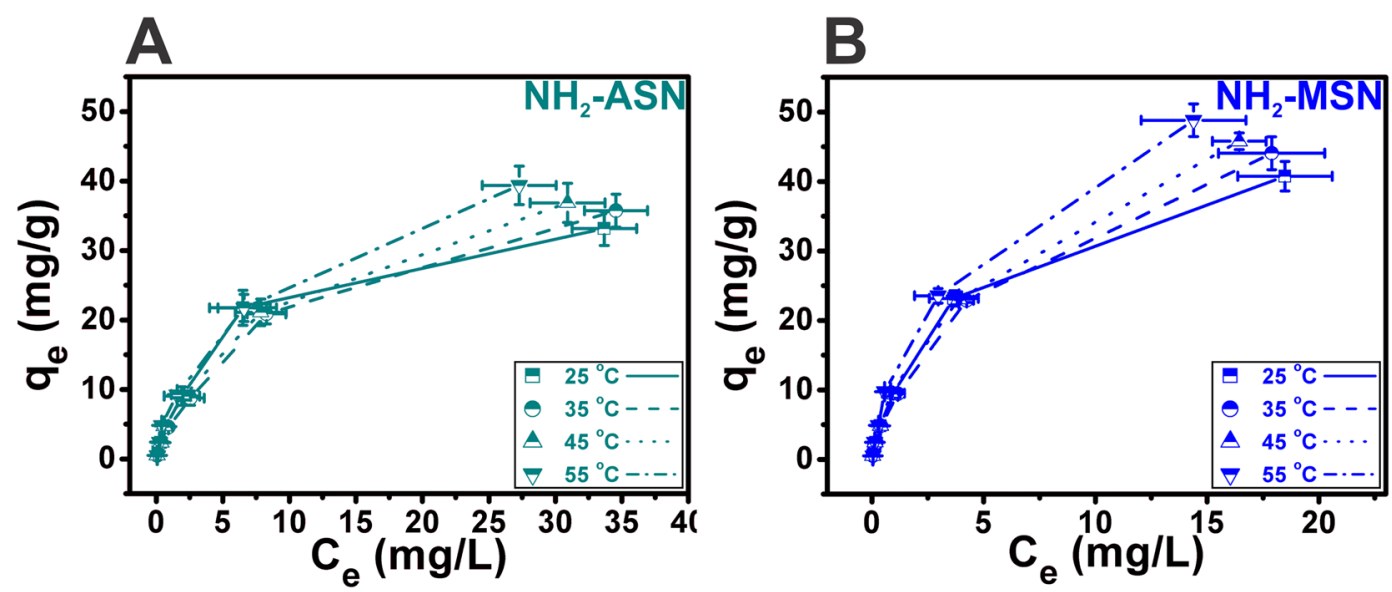

Figure 9. $\mathrm{Cr}(\mathrm{VI})$ adsorption isotherms of $(\mathbf{A}) \mathrm{NH}_{2}-\mathrm{ASNs}$ and (B) $\mathrm{NH}_{2}-\mathrm{MSN}$ as a function of temperature.

be involved in an interplay between intraparticle diffusion and equilibration processes at extremely low $\mathrm{Cr}(\mathrm{VI})$ concentrations. We do not think it is likely that significant desorption of $\mathrm{Cr}(\mathrm{VI})$ occurred because most of the $\mathrm{Cr}(\mathrm{VI})$ adsorbed was reduced to $\mathrm{Cr}(\mathrm{III})$, as determined by XPS, and little $\mathrm{Cr}(\mathrm{VI})$ remained on $\mathrm{NH}_{2}-\mathrm{ASNs}$ and $\mathrm{NH}_{2}$-MSNs during the second and third steps.

Effect of temperature and adsorption isotherm of $\mathbf{N H}_{2}-\mathrm{ASNs}$ and $\mathbf{N H}_{2}-\mathbf{M S N s}$. Figure 9 shows the correlation curves between the equilibrium adsorption capacity $\left(q_{e}\right)$ and equilibrium concentration $\left(C_{e}\right)$ of $\mathrm{Cr}(\mathrm{VI})$ under four different temperatures at $\mathrm{pH}$ of 2.0. The equilibrium adsorption capacity of $\mathrm{NH}_{2}-\mathrm{ASNs}_{\mathrm{Sn}}$ $\mathrm{NH}_{2}-\mathrm{MSNs}$ increased with the increasing of temperature, which was consistent with the results shown in Fig. 5B. To understand the relationship between $q_{e}$ and $C_{e}$ under equilibrium conditions, the adsorption isotherms of $\mathrm{NH}_{2}-\mathrm{ASN}$ and $\mathrm{NH}_{2}-\mathrm{MSN}$ were analyzed by obtaining best fits to data using the extensively used Langmuir, Freundlich, Temkin, and Dubinin-Radushkevich (D-R) models ${ }^{89}$.

Langmuir model, which was primarily designed to describe gas-solid phase adsorption processes, has been often used to quantify the adsorption capacity of various adsorbents in solutions ${ }^{90}$. The Langmuir isotherm was expressed in the following nonlinear and linearized form

$$
\begin{gathered}
q_{e}=\frac{q_{m} K_{L} C_{e}}{K_{L} C_{e}+1} \\
\frac{C_{e}}{q_{e}}=\frac{1}{q_{m}} C_{e}+\frac{1}{q_{m} K_{L}}
\end{gathered}
$$

where $K_{L}\left(\mathrm{~L} \cdot \mathrm{mg}^{-1}\right)$ and $q_{m}\left(\mathrm{mg} \cdot \mathrm{g}^{-1}\right)$ is the Langmuir isotherm constant and the corresponding saturation adsorption capacity, respectively.

Freundlich model has been used to characterize adsorption processes that occur on heterogeneous surfaces ${ }^{91}$. Its isotherm provides useful information on the surface heterogeneity, the exponential distribution of active sites, and their energetics. The Freundlich isotherm was expressed in the following nonlinear and linearized form

$$
\begin{gathered}
q_{e}=K_{F} C_{e}^{\frac{1}{n}} \\
\ln q_{m}=\frac{1}{n} \ln C_{e}+\ln K_{F}
\end{gathered}
$$

where $K_{F}\left(\mathrm{mg} \cdot \mathrm{g}^{-1}\right)$ is the Freundlich isotherm constant that is an approximate indicator of adsorption capacity, while $1 / n$ is the measure of adsorption intensity.

Temkin model takes into account the effects of adsorbate-adsorbate interactions. It assumes that the heat of adsorption of all molecules in the layer decreases linearly rather than logarithmic with the increasing surface coverage $^{92}$. The Temkin isotherm was expressed in the following nonlinear and linearized form

$$
\begin{gathered}
q_{m}=\frac{R T}{b_{T}} \ln \left(K_{T} C_{e}\right) \\
q_{m}=\left(\frac{R T}{b_{T}}\right) \ln C_{e}+\left(\frac{R T}{b_{T}}\right) \ln K_{F}
\end{gathered}
$$



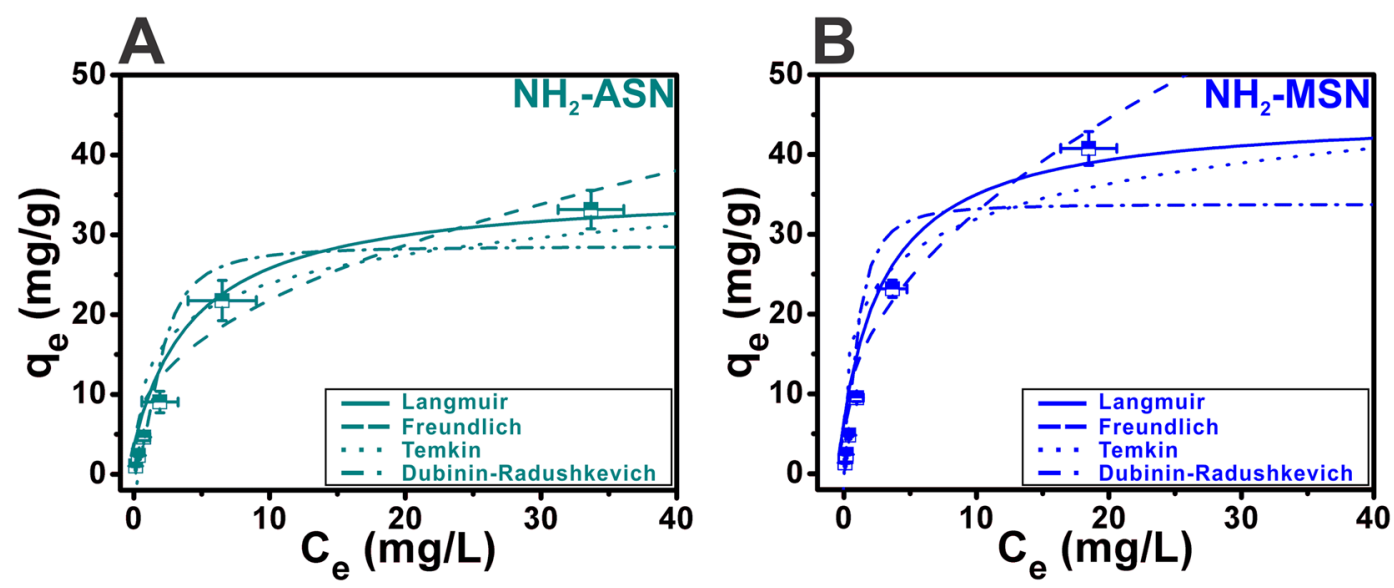

Figure 10. $\mathrm{Cr}(\mathrm{VI})$ adsorption isotherms of $(\mathbf{A}) \mathrm{NH}_{2}-\mathrm{ASNs}$ and $(\mathbf{B}) \mathrm{NH}_{2}-\mathrm{MSNs}$ at $25^{\circ} \mathrm{C}$. Best fits to data were successfully obtained using non-linear fits of the Langmuir, Freundlich, Temkin, and Dubinin-Radushkevich (D-R) models.

where $R\left(8.314 \mathrm{~J} \cdot \mathrm{mol}^{-1} \cdot \mathrm{K}^{-1}\right)$ is the gas constant, $T(\mathrm{~K})$ is the absolute temperature, $K_{T}\left(\mathrm{~L} \cdot \mathrm{g}^{-1}\right)$ is the Temkin isotherm equilibrium binding constant, and $b_{T}$ is the Temkin isotherm constant related to the heat of sorption $\left(\mathrm{J} \cdot \mathrm{mol}^{-1}\right)$.

Dubinin-Radushkevich (D-R) model is a semi-empirical equation in which adsorption follows a pore filling mechanism with Gaussian energy distribution onto heterogeneous surfaces ${ }^{93}$. It has been successfully applied to describe the adsorption of gases on microporous adsorbents quantitatively ${ }^{94}$. The $\mathrm{D}-\mathrm{R}$ isotherm was expressed in the following nonlinear and linearized form

$$
\begin{gathered}
q_{e}=q_{s} \exp \left(-K_{D R} \varepsilon^{2}\right), \quad \varepsilon=R T \ln \left(1+\frac{1}{C_{e}}\right) \\
\ln q_{e}=\ln q_{s}-\left(K_{D R} \varepsilon^{2}\right), \quad \varepsilon=R T \ln \left(1+\frac{1}{C_{e}}\right)
\end{gathered}
$$

where $K_{D R}\left(\mathrm{~mol}^{2} \cdot \mathrm{kJ}^{-2}\right)$ and $q_{s}\left(\mathrm{mg} \cdot \mathrm{g}^{-1}\right)$ is the D-R isotherm constant and the theoretical D-R isotherm saturation capacity, respectively.

Both the nonlinear and linearized form of the four models were used to obtain best fits to adsorption equilibrium data of $\mathrm{NH}_{2}-\mathrm{ASNs}$ and $\mathrm{NH}_{2}-\mathrm{MSNs}$ at $25-55^{\circ} \mathrm{C}$ and $\mathrm{pH}$ of 2.0 . Figure 10 illustrates the results of best fits to the adsorption equilibrium data of $\mathrm{NH}_{2}-\mathrm{ASNs}$ and $\mathrm{NH}_{2}-\mathrm{MSNs}$ using the nonlinear form of the four models. Figure $\mathrm{S} 6$ shows the results of best fits to the adsorption equilibrium data of $\mathrm{NH}_{2}-\mathrm{ASNs}$ and $\mathrm{NH}_{2}-\mathrm{MSNs}$ using the linearized form of the four models. Table S3 summarizes the isotherm parameters and correlation coefficients such as $R^{2}$ and $\chi^{2}$ obtained from best fits to data using the linearized and nonlinear form of the four models, respectively. The value of sum-of-squares (i.e., a measure of scatter of data points around the fitted curve) is used to compute $R^{2}$ and $\chi^{2}$ is similarly calculated by minimizing the sum-of-squares of the nonlinear regression. The validity of each model was confirmed using $R^{2}$ and $\chi^{2}$. According to $R^{2}\left(0.95<R^{2}<0.99\right)$, the Langmuir and Freundlich models could fit the adsorption process reasonably well. However, applying the Langmuir model to the data of $\mathrm{NH}_{2}-\mathrm{ASNs}$ and $\mathrm{NH}_{2}-\mathrm{MSN}$ resulted in improved fits with much smaller $\chi^{2}$ values than the Freundlich model. Consequently, our results suggest that the adsorption process of $\mathrm{NH}_{2}-\mathrm{ASNs}$ and $\mathrm{NH}_{2}-\mathrm{MSNs}_{\text {follows the }}$ Langmuir isotherm better than the Freundlich model. A dimensionless separation factor $R_{L}$, one of the characteristic parameters of the Langmuir isotherm, was defined as

$$
R_{L}=\frac{1}{1+K_{L} C_{0}}
$$

where the value of $K_{L}$ is the fitting parameters listed in Table S3 and the $C_{0}$ is the initial $\mathrm{Cr}(\mathrm{VI})$ ion concentration $\left(0 \leq C_{0} \leq 100\right)$. The value of $R_{L}$ indicates the shape of the Langmuir isotherm to be either unfavorable $\left(R_{L}>1\right)$, linear $\left(R_{L}=1\right)$, favorable $\left(0<R_{L}<1\right)$, or irreversible $\left(R_{L}=0\right)^{95}$. Figure $\mathrm{S} 7$ shows the $R_{L}$ of $\mathrm{NH}_{2}-\mathrm{ASNs}$ and $\mathrm{NH}_{2}-\mathrm{MSN}$ was less than 1 . Note that the values of $R_{L}$ from the Langmuir model and $1 / n$ from the Freundlich (Table S3) all lie between 0 and 1, which corroborates that the adsorption of $\mathrm{Cr}(\mathrm{VI})$ on both $\mathrm{NH}_{2}-\mathrm{ASNs}$ and $\mathrm{NH}_{2}-\mathrm{MSNs}$ is a favorable process with the maximum adsorption capacity of $\mathrm{NH}_{2}-\mathrm{MSNs} \sim 1.3$ times greater than that of $\mathrm{NH}_{2}-\mathrm{ASNs}$.

Adsorption thermodynamics of $\mathrm{NH}_{2}-\mathrm{ASNs}$ and $\mathrm{NH}_{2}-\mathbf{M S N s}$. Thermodynamic parameters of the adsorption process, such as change in standard free energy $\left(\Delta G^{\circ}\right)$, enthalpy $\left(\Delta H^{\circ}\right)$, and entropy $\left(\Delta S^{\circ}\right)$ can be 


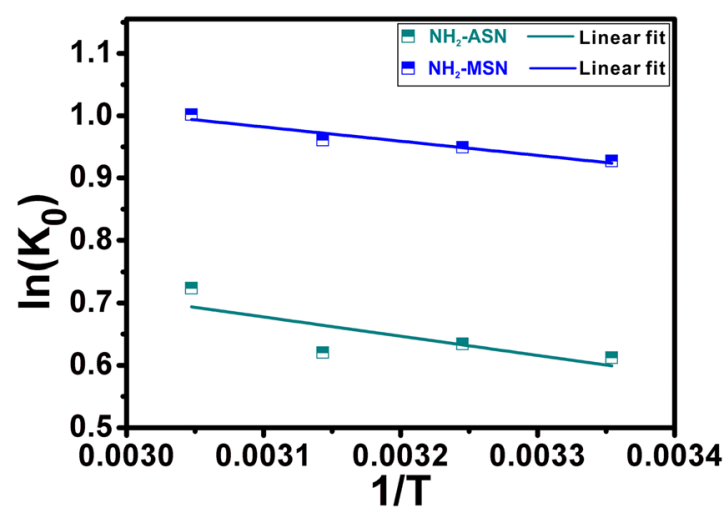

Figure 11. Plot of $\ln \left(K_{0}\right)$ of $\mathrm{NH}_{2}-\mathrm{ASNs}$ (dark cyan) and $\mathrm{NH}_{2}-\mathrm{MSNs}$ (blue) versus inverse temperature $(1 / T)$. Best fits to data were successfully obtained using the linear regression of Eq. 26.

\begin{tabular}{|c|c|c|c|c|c|c|}
\hline \multirow[b]{2}{*}{ Temperature (K) } & \multicolumn{3}{|l|}{$\mathrm{NH}_{2}-\mathrm{ASN}$} & \multicolumn{3}{|l|}{$\mathrm{NH}_{2}-\mathrm{MSN}$} \\
\hline & $\Delta \mathrm{G}\left(\mathrm{kJ} \mathrm{mol}^{-1}\right)$ & $\Delta \mathrm{H}\left(\mathrm{kJ} \mathrm{mol}^{-1}\right)$ & $\Delta \mathrm{S}\left(\mathrm{J} \mathrm{mol}^{-1} \mathrm{~K}^{-1}\right)$ & $\Delta \mathrm{G}\left(\mathrm{kJ} \mathrm{mol}^{-1}\right)$ & $\Delta \mathrm{H}\left(\mathrm{kJ} \mathrm{mol}{ }^{-1}\right)$ & $\Delta \mathrm{S}\left(\mathrm{J} \mathrm{mol}^{-1} \mathrm{~K}^{-1}\right)$ \\
\hline 298.15 & -1.5792 & 2.5654 & 13.587 & -2.2985 & 1.8994 & 14.052 \\
\hline 308.15 & -1.6251 & & & -2.4317 & & \\
\hline 318.15 & -1.6409 & & & -2.5412 & & \\
\hline 328.15 & -1.9742 & & & -2.7329 & & \\
\hline
\end{tabular}

Table 4. Thermodynamic parameters for $\mathrm{Cr}(\mathrm{VI})$ adsorption on $\mathrm{NH}_{2}-\mathrm{ASN}$ and $\mathrm{NH}_{2}-\mathrm{MSN}$ obtained from the linear regression shown in Fig. 11.

estimated from the data of the adsorption isotherm measured at various temperatures according to Eqs. 24, 25, and 26

$$
\begin{gathered}
K_{0}=\lim _{C_{e} \rightarrow 0} \frac{q_{e}}{C_{e}} \\
\Delta G^{\circ}=-R T \ln K_{0}=\Delta H^{\circ}-T \Delta S^{\circ} \\
\ln K_{0}=-\frac{\Delta H^{\circ}}{R} \frac{1}{T}+\frac{\Delta S^{\circ}}{R}
\end{gathered}
$$

where $K_{0}$ is the adsorption distribution coefficient, which was obtained by plotting $\ln \left(q_{e} / C_{e}\right)$ versus $C_{e}$ at different temperatures and extrapolating to zero $C_{e}{ }^{96}, \Delta H^{\circ}\left(\mathrm{kJ} \cdot \mathrm{mol}^{-1}\right)$ is the standard enthalpy change, $\Delta S^{\circ}\left(\mathrm{J} \cdot \mathrm{mol}^{-1} \cdot \mathrm{K}^{-1}\right)$ is the standard entropy change, $\Delta G^{\circ}\left(\mathrm{kJ} \cdot \mathrm{mol}^{-1}\right)$ is the standard free energy change, $R\left(8.314 \mathrm{~J} \cdot \mathrm{mol}^{-1} \cdot \mathrm{K}^{-1}\right)$ is the gas constant, and $T(\mathrm{~K})$ is the absolute temperature, respectively. $\Delta H^{\circ}$ and $\Delta S^{\circ}$ were obtained from the slope and intercept of the curve based on the well-known van't Hoff equation (Eq. 27)

$$
\ln \left(\frac{K_{0}\left(T_{2}\right)}{K_{0}\left(T_{1}\right)}\right)=-\frac{\Delta H^{\circ}}{R}\left[\frac{1}{T_{2}}-\frac{1}{T_{1}}\right]
$$

Figure 11 and Table 4 show the plot of $\ln K_{0}$ versus $1 / T$ and the corresponding thermodynamic parameters of $\mathrm{Cr}(\mathrm{VI})$ adsorption on $\mathrm{NH}_{2}-\mathrm{ASNs}$ and $\mathrm{NH}_{2}-\mathrm{MSNs}$, repectively. According to Karthik et al., the adsorption process is mainly governed by electrostatic interaction between adsorption sites and adsorbing ions if the magnitude of $\Delta H^{\circ}$ lies between 2.1 and $20.9 \mathrm{~kJ} \cdot \mathrm{mol}^{-197}$. Note that $\Delta H^{\circ}$ of $\mathrm{NH}_{2}-\mathrm{ASNs}$ and $\mathrm{NH}_{2}-\mathrm{MSNs}$ listed in Table 4 was 2.6 and $1.9 \mathrm{~kJ} \cdot \mathrm{mol}^{-1}$, respectively. These values were nearby the range $\left(2.1 \mathrm{~kJ} \cdot \mathrm{mol}^{-1} \leq \Delta H^{\circ} \leq 20.9 \mathrm{~kJ} \cdot \mathrm{mol}^{-1}\right)$, indicating the process was likely electrostatic physisorption. The positive values of $\Delta H^{\circ}$ revealed the endothermic nature of the adsorption process, which was consistent with the results of temperature-dependent adsorption isotherms. In general, all $\Delta G^{\circ}$ values of $\mathrm{NH}_{2}-\mathrm{ASNs}$ and $\mathrm{NH}_{2}-\mathrm{MSNs}$ were negative for the temperatures from 25 to $55^{\circ} \mathrm{C}$, exhibiting that the adsorption was a spontaneous process. The $\Delta G^{\circ}$ of $\mathrm{NH}_{2}-\mathrm{MSN}$ was approximately $\sim 1.5$ times greater than that of $\mathrm{NH}_{2}-\mathrm{ASN}$ likely due to the presence of nanopores. The positive value of $\Delta S^{\circ}$ suggests the increased randomness at the liquid-solid interface during $\mathrm{Cr}(\mathrm{VI})$ adsorption likely indicates the process is an entropy-driven process rather than enthalpy ${ }^{97}$.

Effect of foreign ions on $\mathrm{Cr}(\mathrm{VI})$ removal efficiency of $\mathrm{NH}_{2}-\mathrm{ASNs}$ and $\mathrm{NH}_{2}-\mathrm{MSNs}$. Figure 12 shows the effect of foreign ions such as $\mathrm{Na}^{+}, \mathrm{K}^{+}, \mathrm{Ca}^{2+}, \mathrm{Mg}^{2+}, \mathrm{Zn}^{2+}$, and $\mathrm{Fe}^{2+}$ on the $\mathrm{Cr}(\mathrm{VI})$ removal efficiency $(R)$ of $\mathrm{NH}_{2}-\mathrm{ASNs}$ and $\mathrm{NH}_{2}-\mathrm{MSNs}$ with $\mathrm{Cr}(\mathrm{VI})$ concentration of $100 \mathrm{mg} / \mathrm{L}$ at $25^{\circ} \mathrm{C}$. The results indicated that the 


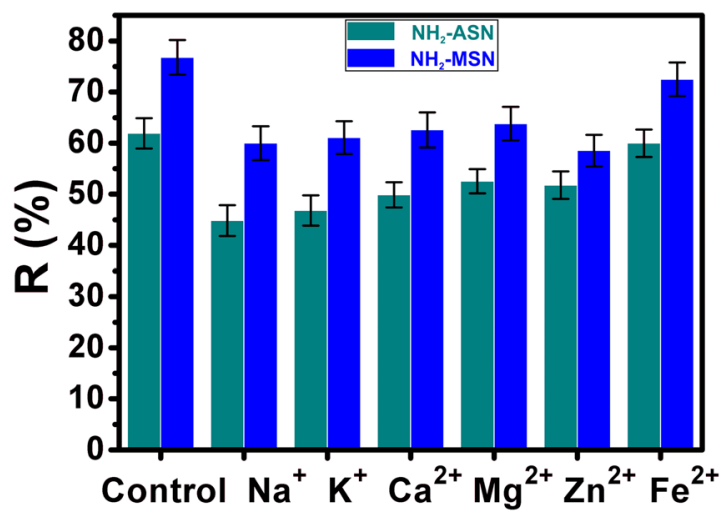

Figure 12. Effect of foreign ions on $\mathrm{Cr}(\mathrm{VI})$ removal by $\mathrm{NH}_{2}-\mathrm{ASNs}$ (dark cyan) and $\mathrm{NH}_{2}-\mathrm{MSNs}$ (blue).

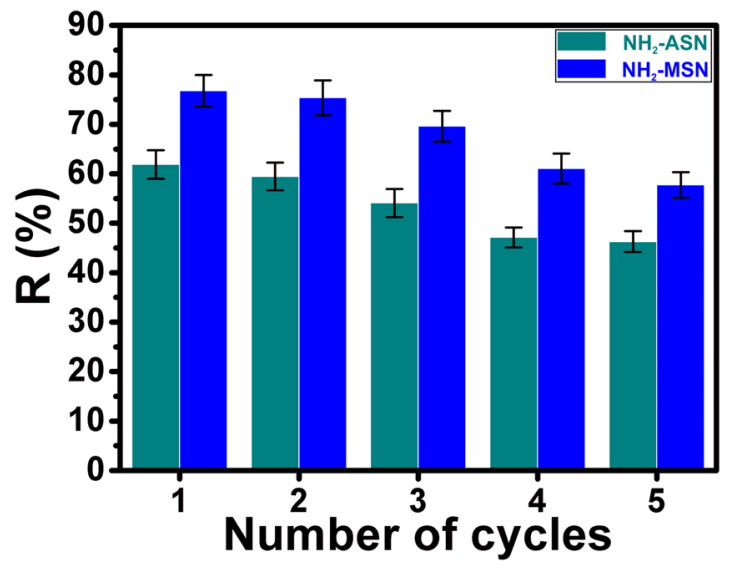

Figure 13. Desorption-regeneration of $\mathrm{NH}_{2}-\mathrm{ASNs}$ (dark cyan) and $\mathrm{NH}_{2}-\mathrm{MSNs}$ (blue) for $\mathrm{Cr}(\mathrm{VI})$ removal.

adsorption capacity of $\mathrm{NH}_{2}-\mathrm{ASN}$ and $\mathrm{NH}_{2}-\mathrm{MSNs}$ slightly declined with the presence of the foreign ions by no more than 28 and $22 \%$ of the control, respectively. Note that monovalent cations exerted a slightly more influence on the $\mathrm{Cr}(\mathrm{VI})$ removal performance of $\mathrm{NH}_{2}-\mathrm{ASNs}$ and $\mathrm{NH}_{2}-\mathrm{MSN}$ than multivalent ions. The adverse effect of foreign cations on the uptake of $\mathrm{Cr}(\mathrm{VI})$ ions has been attributed to the presence of ion exchange during the adsorption process ${ }^{98,99}$. Under the circumstance of increased number of the foreign cations, the electrostatic attraction between the negatively charged $\mathrm{Cr}(\mathrm{VI})$ ions and the positively charged $\mathrm{NH}_{3}{ }^{+}$-groups becomes weaker, resulting in inhibiting the adsorption of $\mathrm{Cr}(\mathrm{VI})$ ions, and thus the decline of $R$. Nevertheless, our findings suggest that $\mathrm{NH}_{2}-\mathrm{MSNs}$ exhibit a robust and high enough $\mathrm{Cr}(\mathrm{VI})$ removal performance marginally better than $\mathrm{NH}_{2}-$ ASNs under the influence of foreign ions.

Desorption-regeneration of $\mathrm{NH}_{2}-\mathrm{ASN}$ and $\mathrm{NH}_{2}-$ MSNs. Desorption-regeneration experiments of $\mathrm{NH}_{2}-\mathrm{ASN}$ and $\mathrm{NH}_{2}-\mathrm{MSN}$ were carried out to assess the feasibility of their recovery and future usage. Figure 13 shows the removal efficiencies $(R)$ of $\mathrm{NH}_{2}-\mathrm{ASNs}$ and $\mathrm{NH}_{2}-\mathrm{MSNs}$ after five cycles of desorption-regeneration with $0.1 \mathrm{M} \mathrm{HCl}$ solution at temperature and $\mathrm{pH}$ of $25^{\circ} \mathrm{C}$ and 2.0 . The removal efficiency $(R)$ of $\mathrm{NH}_{2}-\mathrm{ASNs}$ and $\mathrm{NH}_{2}-\mathrm{MSNs}$ after five regenerations had slightly decreased from 61.9 to 46.3 and 76.8 to $57.8 \%$, respectively. The reduction of their removal efficiency after five cycles was only less than $25 \%$ of the starting value, which suggests that $\mathrm{NH}_{2}-\mathrm{ASNs}$ and $\mathrm{NH}_{2}-\mathrm{MSNs}$ may have a promising recycling property for $\mathrm{Cr}(\mathrm{VI})$ removal.

\section{Conclusions}

We present a comprehensive analysis of $\mathrm{Cr}(\mathrm{VI})$ adsorption and removal on both bare and $\mathrm{NH}_{2}$-functionalized ASNs and MSNs in aqueous environments. Highly monodisperse ASNs and MSNs of approximately equal sizes were successfully synthesized using modifications of the Stöber method and subsequently surface functionalized with amine groups. The specific surface area of MSNs (as obtained by $\mathrm{N}_{2}$ sorption measurements) was twice as large as that of ASNs, and the $\mathrm{NH}_{2}$-functional group loading value of APTES reacted MSNs was four times greater than that of APTES reacted ASNs. Further analyses of $\mathrm{N}_{2}$ sorption measurements using a simple geometric scaling approach revealed that more than $70 \%$ of the total specific surface area of MSNs and $\mathrm{NH}_{2}-\mathrm{MSNs}_{\mathrm{N}}$ was attributable to nanopores within MSNs and $\mathrm{NH}_{2}-\mathrm{MSNs}$, respectively. Furthermore, the specific surface areas of ASNs and MSNs decreased as APTES surface loading increased. $\mathrm{Cr}(\mathrm{VI})$ adsorption and removal efficiencies were determined using a series of kinetic adsorption batch experiments. The kinetics of the $\mathrm{Cr}(\mathrm{VI})$ adsorption 
processes exhibited a rapid adsorption whereby $\sim 90 \%$ of $\mathrm{Cr}(\mathrm{VI})$ adsorption was achieved within a minute. Fits with experimental data of the pseudo-first and pseudo-second order kinetic models were investigated, and the intraparticle diffusion model was also applied in an attempt to understand the mechanism of the adsorption process. Best fits with experimental data were obtained by applying nonlinear fits to the pseudo-second order model. The outcomes of fitting processes were verified by evaluating standard residuals (SRs) rather than correlation coefficients $\left(R^{2}\right)$. Application of the intraparticle diffusion model also resulted in good fits with kinetic data and indicated adsorption might involve multiple steps. The adsorption isotherms were analyzed as a function of temperature by nonlinear and linearized regression, and the Langmuir model resulted in best fits to the isotherms. The thermodynamic parameters indicated that the adsorption of $\mathrm{Cr}(\mathrm{VI})$ on $\mathrm{NH}_{2}-\mathrm{ASNs}$ and $\mathrm{NH}_{2}-\mathrm{MSNs}$ was endothermic in nature and an entropy-driven spontaneous process. The results of desorption-regeneration experiments suggest that $\mathrm{NH}_{2}-\mathrm{ASNs}$ and $\mathrm{NH}_{2}-\mathrm{MSNs}$ may have a promising potential for recycling. Although the specific surface areas of $\mathrm{NH}_{2}-\mathrm{ASNs}$ and $\mathrm{NH}_{2}-\mathrm{MSNs}$ were lower than those of ASNs and MSNs, $\mathrm{NH}_{2}-\mathrm{ASNs}$ and $\mathrm{NH}_{2}-\mathrm{MSNs}$ had significantly higher $\mathrm{Cr}(\mathrm{VI})$ adsorption capacities (34.0 and $42.2 \mathrm{mg} \cdot \mathrm{g}^{-1}$, respectively) and removal efficiencies (61.9 and 76.8\%, respectively). These values compare reasonably well with those reported for powder-like mesoporous silica, Stöber silica, and hybrid silica nanoparticles ${ }^{27,39,76,100}$. Furthermore, these results suggest both the introduction of nanoporous architecture and appropriate chemical functionalization of nanoparticle surfaces are essential for enhancing $\mathrm{Cr}(\mathrm{VI})$ adsorption and removal process.

The findings of the current study are significant in two respects. First, they show silica nanoparticles possessing well-defined sizes and shapes with narrow distributions can be produced and chemically functionalized ${ }^{34}$. The spherical geometry of the nanoparticles provided admittedly simplified modeling interactions between them and $\mathrm{Cr}(\mathrm{VI})$ and facilitated the study of $\mathrm{Cr}(\mathrm{VI})$ adsorption processes. In the present study, we used model systems and material characterization tools to investigate $\mathrm{Cr}$ adsorption on silica nanoparticles and the results suggest a structural and chemical rationale for enhanced $\mathrm{Cr}(\mathrm{VI})$ adsorption and removal. Second, the $\mathrm{NH}_{2}-\mathrm{ASNs}$ and $\mathrm{NH}_{2}-\mathrm{MSNs}$ examined converted most of the adsorbed $\mathrm{Cr}(\mathrm{VI})$ to relatively non-toxic $\mathrm{Cr}$ (III) at levels comparable to or marginally better than those reported for similar mesoporous silica systems ${ }^{6,38,75,76,100}$. Our results suggest $\mathrm{Cr}(\mathrm{VI})$ reduction is caused by a mixed adsorption-partial reduction process that may be characteristic of functionalized nanoparticle-based systems $s^{6,73,101,102}$. Understanding the detailed mechanism of $\mathrm{Cr}$ ( VI) to $\mathrm{Cr}$ (III) conversion represents a meaningful step toward the goal of removing toxic $\mathrm{Cr}(\mathrm{VI})$ from wastewater environments.

\section{Data availability}

All data generated or analyzed during this study are included within the article and are available from the corresponding author upon request.

Received: 7 December 2019; Accepted: 27 February 2020;

Published online: 27 March 2020

\section{References}

1. US Department of Health and Human Services, Toxicological Profile for Chromium. Public Health Services Agency for Toxic Substances and Diseases Registry, Washington DC (2012).

2. Raghunathan, V. K., Tettey, J. N., Ellis, E. M. \& Grant, M. H. Comparative chronic in vitro toxicity of hexavalent chromium to osteoblasts and monocytes. J. Biomed. Mater. Res. A 88, 543-550 (2009).

3. Zhitkovich, A. Chromium in drinking water: sources, metabolism, and cancer risks. Chem. Res. Toxicol. 24, 1617-1629 (2011).

4. Megharaj, M., Avudainayagam, S. \& Naidu, R. Toxicity of hexavalent chromium and its reduction by bacteria isolated from soil contaminated with tannery waste. Curr. Microbiol. 47, 51-54 (2003).

5. Katz, S. A. Salem, H. The biological and environmental chemistry of chromium. (VCH Publishers, New York, 1994).

6. Fellenz, N. et al. Chromium (VI) removal from water by means of adsorption-reduction at the surface of amino-functionalized MCM-41 sorbents. Micropor. Mesopor. Mater. 239, 138-146 (2017).

7. Selvi, K., Pattabhi, S. \& Kadirvelu, K. Removal of Cr(VI) from aqueous solution by adsorption onto activated carbon. Bioresour. Technol. 80, 87-89 (2001).

8. Yang, T. et al. Synthesis of Na-X zeolite from low aluminum coal fly ash: Characterization and high efficient $\mathrm{As}(\mathrm{V})$ removal. $A d v$. Powder Technol. 30, 199-206 (2019).

9. Yang, T., Han, C., Tang, J. \& Luo, Y. Removal performance and mechanisms of Cr(VI) by an in-situ self-improvement of mesoporous biochar derived from chicken bone. Environ. Sci. Pollut. Res., https://doi.org/10.1007/s11356-019-07116-4 (2019).

10. Li, L.-L., Feng, X.-Q., Han, R.-P., Zang, S.-Q. \& Yang, G. Cr(VI) removal via anion exchange on a silver-triazolate MOF. J. Hazard. Mater. 321, 622-628 (2017).

11. Galan, B., Castaneda, D. \& Ortiz, I. Removal and recovery of $\mathrm{Cr}(\mathrm{VI})$ from polluted ground waters: A comparative study of ionexchange technologies. Water Res. 39, 4317-4324 (2005).

12. Kozlowski, C. A. \& Walkowiak, W. Removal of chromium(VI) from aqueous solutions by polymer inclusion membranes. Water Res. 36, 4870-4876 (2002).

13. Riaz, T. et al. Synthesis and characterization of polyurethane-cellulose acetate blend membrane for chromium (VI) removal. Carbohyd. Polym. 153, 582-591 (2016).

14. Adhoum, N., Monser, L., Bellakhal, N. \& Belgaied, J.-E. Treatment of electroplating wastewater containing $\mathrm{Cu}^{2+}, \mathrm{Zn}^{2+}$ and $\mathrm{Cr}$ (VI) by electrocoagulation. J. Hazard. Mater. 112, 207-213 (2004).

15. Gheju, M. \& Balcu, I. Removal of chromium from $\mathrm{Cr}(\mathrm{VI})$ polluted wastewaters by reduction with scrap iron and subsequent precipitation of resulted cations. J. Hazard. Mater. 196, 131-138 (2011).

16. Golbaz, S., Jafari, A. J., Rafiee, M. \& Kalantary, R. R. Separate and simultaneous removal of phenol, chromium, and cyanide from aqueous solution by coagulation/precipitation: Mechanisms and theory. Chem. Eng. J. 253, 251-257 (2014).

17. Dupont, L. \& Guillon, E. Removal of hexavalent chromium with a lignocellulosic substrate extracted from wheat bran. Environ. Sci. Technol. 37, 4235-4241 (2003).

18. Peng, C., Meng, H., Song, S., Lu, S. \& Lopez-Valdivieso, A. Elimination of $\mathrm{Cr}(\mathrm{VI})$ from electroplating wastewater by electrodialysis following chemical precipitation. Sep. Sci. Technol. 39, 1501-1517 (2004).

19. Kongsricharoern, N. \& Polprasert, C. Chromium removal by a bipolar electro-chemical precipitation process. Water Sci. Technol. 34, 109-116 (1996). 
20. Chen, T., Zhou, Z., Xu, S., Wang, H. \& Lu, W. Adsorption behavior comparison of trivalent and hexavalent chromium on biochar derived from municipal sludge. Bioresour. Technol. 190, 388-394 (2015).

21. Hu, Z., Lei, L., Li, Y. \& Ni, Y. Chromium adsorption on high-performance activated carbons from aqueous solution. Sep. Purif. Technol. 31, 13-18 (2003).

22. Luo, C., Tian, Z., Yang, B., Zhang, L. \& Yan, S. Manganese dioxide/iron oxide/acid Oxidized multi-walled carbon nanotube magnetic nanocomposite for enhanced hexavalent chromium removal. Chem. Eng. J. 234, 256-265 (2013).

23. Kobielska, P. A., Howarth, A. J., Farha, O. K. \& Nayak, S. Metal-organic frameworks for heavy metal removal from water. Coordin. Chem. Rev. 358, 92-107 (2018)

24. Duranoglu, D., Kaya, I. G. B., Beker, U. \& Senkal, B. F. Synthesis and adsorption properties of polymeric and polymer-based hybrid adsorbent for hexavalent chromium removal. Chem. Eng. J. 181, 103-112 (2012).

25. Bai, R. S. \& Abraham, T. E. Studies on chromium(VI) adsorption-desorption using. immobilized fungal biomass. Bioresour. Technol. 87, 17-26 (2003).

26. Abdel-Halim, E. S. \& Al-Deyab, S. S. Removal of heavy metals from their aqueous solutions through adsorption onto natural polymers. Carbohyd. Polym. 84, 454-458 (2011).

27. Dinker, M. K. \& Kulkarni, P. S. Recent Advances in Silica-Based Materials for the Removal of Hexavalent Chromium: A Review. J. Chem. Eng. Data 60, 2521-2540 (2015)

28. Plumeré, N., Ruff, A., Speiser, B., Feldmann, V. \& Mayer, H. A. Stöber silica particles as basis for redox modifications: Particle shape, size, polydispersity, and porosity. J. Colloid Interface Sci. 368, 208-219 (2012).

29. Hyde, E. D. E. R., Seyfaee, A., Neville, F. \& Moreno-Atanasio, R. Colloidal Silica Particle Synthesis and Future Industrial Manufacturing Pathways: A Review. Ind. Eng. Chem. Res. 55, 8891-8913 (2016).

30. Kim, M. J. \& Ryoo, R. Synthesis and pore size control of cubic mesoporous silica SBA-1. Chem. Mater. 11, 487-491 (1999).

31. Zhao, D., Sun, J., Li, Q. \& Stucky, G. D. Morphological control of highly ordered mesoporous silica SBA-15. Chem. Mater. 12, 275-279 (2000).

32. Lin, H. P. et al. The synthesis and application of the mesoporous molecular sieves MCM-41 - A review. J. Chin. Chem. Soc-Taip. 46, 495-507 (1999).

33. Kim, T. W., Chung, P. W. \& Lin, V. S. Y. Facile Synthesis of Monodisperse Spherical MCM-48 Mesoporous Silica Nanoparticles with Controlled Particle Size. Chem. Mater. 22, 5093-5104 (2010).

34. Slowing, I. I., Vivero-Escoto, J. L., Trewyn, B. G. \& Lin, V. S. Y. Mesoporous silica nanoparticles: structural design and applications. J. Mater. Chem. 20, 7924-7937 (2010).

35. Delaney, P. et al. Porous silica spheres as indoor air pollutant scavengers. J. Environ. Monitor. 12, 2244-2251 (2010).

36. Kumar, A. et al. Direct air capture of $\mathrm{CO}_{2}$ by physisorbent materials. Angew. Chem. Int. Ed. 54, 14372-14377 (2015).

37. Flynn, E. J., Keane, D. A., Tabari, P. M. \& Morris, M. A. Pervaporation performance enhancement through the incorporation of mesoporous silica spheres into PVA membranes. Sep. Purif. Technol. 118, 73-80 (2013).

38. Li, J. et al. Synthesis, amino-functionalization of mesoporous silica and its adsorption of $\mathrm{Cr}(\mathrm{VI})$. J. Colloid Interface Sci. 318 , 309-314 (2008).

39. Lee, J. H. et al. Investigation of the mechanism of chromium removal in (3-aminopropyl)trimethoxysilane functionalized mesoporous silica. Sci. Rep. 8, 12078 (2018)

40. Soliman, E. M. Synthesis and Metal Collecting Properties of Mono, Di, Tri and Tetramine Based on Silica Gel Matrix. Anal. Lett. 30, 1739-1751 (1997)

41. Manu, V., Mody, H. M., Bajaj, H. C. \& Jasra, R. V. Adsorption of $\mathrm{Cu}^{2+}$ on Amino Functionalized Silica Gel with Different Loading. Ind. Eng. Chem. Res. 48, 8954-8960 (2009).

42. Stöber, W., Fink, A. \& Bohn, E. Controlled Growth of Monodisperse Silica Spheres in the Micron Size Range. J. Colloid Interface Sci. 26, 62-69 (1968).

43. Thomassen, L. C. J. et al. Synthesis and characterization of stable monodisperse silica nanoparticle sols for in vitro cytotoxicity testing. Langmuir 26, 328-335 (2010).

44. Van Blaaderen, A. \& Kentgens, A. P. M. Particle morphology and chemical microstructure of colloidal silica spheres made from alkoxysilanes. J. Non-Cryst. Solids 149, 161-178 (1992).

45. Moller, K., Kobler, J. \& Bein, T. Colloidal suspensions of nanometer-sized mesoporous silica. Adv. Funct. Mater. 17, 605-612 (2007).

46. Lv, X., Zhang, L., Xing, F. \& Lin, H. Controlled synthesis of monodispersed mesoporous silica nanoparticles: Particle size tuning and formation mechanism investigation. Micropor. Mesopor. Mater. 225, 238-244 (2016).

47. Park, J. W., Park, Y. J. \& Jun, C. H. Post-grafting of silica surfaces with pre-functionalized organosilanes: new synthetic equivalents of conventional trialkoxysilanes. Chem. Commun. 47, 4860-4871 (2011).

48. Fellenz, N., Martin, P., Marchetti, S. \& Bengoa, F. Aminopropyl-modified mesoporous silica nanospheres for the adsorption of $\mathrm{Cr}(\mathrm{VI})$ from water. J. Porous Mater. 22, 729-738 (2015).

49. Ju, J. et al. Accelerated redox reaction between chromate and phenolic pollutants during freezing. J. Hazard. Mater. 329, 330-338 (2017).

50. APHA. Standard Method for the Examination of Water and Wastewater. 16th edn, (American Public Health Association, Washington DC, 1985).

51. Xiao, Y., Azaiez, J. \& Hill, J. M. Erroneous Application of Pseudo-Second-Order Adsorption Kinetics Model: Ignored Assumptions and Spurious Correlations. Ind. Eng. Chem. Res. 57, 2705-2709 (2018).

52. Blanchard, G., Maunaye, M. \& Martin, G. Removal of heavy metals from waters by means of natural zeolites. Water Res. 18, $1501-1507$ (1984).

53. Ho, Y. S. \& McKay, G. A Comparison of Chemisorption Kinetic Models Applied to Pollutant Removal on Various Sorbents. Process Saf. Environ. Prot. 76, 332-340 (1998).

54. Azizian, S. Kinetic models of sorption: a theoretical analysis. J. Colloid Interface Sci. 276, 47-52 (2004).

55. Ho, Y. S. Review of second-order models for adsorption systems. J. Hazard. Mater. 136, 681-689 (2006).

56. Weber, W. J. \& Morris, J. C. Advances in water pollution research. In Proceedings of the First International Conference on Water Pollution Research. 2, 231 (Pergamon Press Oxford, 1962).

57. Akram, M., Bhatti, H. N., Iqbal, M., Noreen, S. \& Sadaf, S. Biocomposite efficiency for $\mathrm{Cr}(\mathrm{VI})$ adsorption: Kinetic, equilibrium and thermodynamics studies. J. Environ. Chem. Eng. 5, 400-411 (2017).

58. Kirk, C. T. Quantitative-Analysis of the Effect of Disorder-Induced Mode-Coupling on Infrared-Absorption in Silica. Phys. Rev. B 38, 1255-1273 (1988).

59. Kim, B. G., Kang, S. Y. \& Kim, J. J. FTIR study of fluorinated silicon oxide film. J. Phys. D Appl. Phys. 30, 1720-1724 (1997).

60. Chong, A. S. M. \& Zhao, X. S. Functionalization of SBA-15 with APTES and characterization of functionalized materials. J. Phys. Chem. B 107, 12650-12657 (2003).

61. Ebrahimi-Gatkash, M., Younesi, H., Shahbazi, A. \& Heidari, A. Amino-functionalized mesoporous MCM-41 silica as an efficient adsorbent for water treatment: batch and fixed-bed column adsorption of the nitrate anion. Appl. Water Sci. 7, 1887-1901 (2017).

62. Sing, K. S. W. et al. International Union of Pure and Applied Chemistry: reporting physisorption data for gas/solid systems with special reference to the determination of surface area and porosity. Pure Appl. Chem. 57, 603-619 (1985).

63. Balbuena, P. B. \& Gubbins, K. E. Theoretical interpretation of adsorption behavior of simple fluids in slit pores. Langmuir 9 , 1801-1814 (1993). 
64. Thommes, M. \& Cychosz, K. A. Physical adsorption characterization of nanoporous materials: progress and challenges. Adsorption 20, 233-250 (2014).

65. Thommes, M. et al. Physisorption of gases, with special reference to the evaluation of surface area and pore size distribution (IUPAC Technical Report). Pure Appl. Chem. 87, 1051-1069 (2015).

66. Brunauer, S., Emmett, P. H. \& Teller, E. Adsorption of Gases in Multimolecular Layers. J. Am. Chem. Soc. 60, 309-319 (1938).

67. Barrett, E. P., Joyner, L. G. \& Halenda, P. P. The Determination of Pore Volume and Area Distributions in Porous Substances. I. Computations from Nitrogen Isotherms. J. Am. Chem. Soc. 73, 373-380 (1951).

68. Giesche, H., Unger, K. K., Muller, U. \& Esser, U. Hysteresis in Nitrogen Sorption and Mercury Porosimetry on Mesoporous Model Adsorbents Made of Aggregated Monodisperse Silica Spheres. Colloid Surf. 37, 93-113 (1989).

69. Legrand, A. P. The surface properties of silicas. (Wiley, 1998).

70. Gregg, S. J. \& Sing, K. S. W. The physical adsorption of gases by nonporous solids: The type II isotherm. Adsorption, surface area and porosity 41-110 (Academic Press, London, 1982).

71. Etienne, M. \& Walcarius, A. Analytical investigation of the chemical reactivity and stability of aminopropyl-grafted silica in aqueous medium. Talanta 59, 1173-1188 (2003).

72. Oh, Y. J., Song, H., Shin, W. S., Choi, S. J. \& Kim, Y. H. Effect of amorphous silica and silica sand on removal of chromium(VI) by zero-valent iron. Chemosphere 66, 858-865 (2007).

73. Zaitseva, N., Zaitsev, V. \& Walcarius, A. Chromium(VI) removal via reduction-sorption on bi-functional silica adsorbents. J. Hazard. Mater. 250-251, 454-461 (2013).

74. Yoshitake, H., Yokoi, T. \& Tatsumi, T. Adsorption of Chromate and Arsenate by Amino-Functionalized MCM-41 and SBA-1. Chem. Mater. 14, 4603-4610 (2002).

75. Lam, K. F., Yeung, K. L. \& Mckay, G. Selective mesoporous adsorbents for $\mathrm{Cr}_{2} \mathrm{O}_{7}{ }^{2-}$ and $\mathrm{Cu}^{2+}$ separation. Micropor. Mesopor. Mat. 100, 191-201 (2007)

76. Li, J. et al. Different N-containing functional groups modified mesoporous adsorbents for $\mathrm{Cr}(\mathrm{VI})$ sequestration: Synthesis, characterization and comparison. Micropor. Mesopor. Mat. 110, 442-450 (2008).

77. Thakur, S. S. \& Chauhan, G. S. Gelatin-Silica-Based Hybrid Materials as Efficient Candidates for Removal of Chromium(Vi) from Aqueous Solutions. Ind. Eng. Chem. Res. 53, 4838-4849 (2014).

78. Samiey, B., Cheng, C.-H. \& Wu, J. Organic-Inorganic Hybrid Polymers as Adsorbents for Removal of Heavy Metal Ions from Solutions: A Review. Materials 7, 673-726 (2014).

79. Lenshin, A. S., Kashkarov, V. M., Domashevskaya, E. P., Bel'tyukov, A. N. \& Gil'mutdinov, F. Z. Investigations of the composition of macro-, micro- and nanoporous silicon surface by ultrasoft X-ray spectroscopy and X-ray photoelectron spectroscopy. Appl. Surf. Sci. 359, 550-559 (2015).

80. Swart, H. C., van Hattum, E. D., Arnoldbik, W. M. \& Habraken, F. H. P. M. Comparison of $\mathrm{SiO}_{\mathrm{x}}$ structure in RF sputtered samples. phys. status solidi c 1, 2286-2291 (2004).

81. Bywalez, R., Karacuban, H., Nienhaus, H., Schulz, C. \& Wiggers, H. Stabilization of mid-sized silicon nanoparticles by functionalization with acrylic acid. Nanoscale Res. Lett. 7, 76 (2012).

82. Moulder, J. F., Chastain, J. \& King, R. C. Handbook of X-ray Photoelectron Spectroscopy: A Reference Book of Standard Spectra for Identification and Interpretation of XPS Data. (Physical Electronics, 1995).

83. Calvo, A. et al. Mesoporous Aminopropyl-Functionalized Hybrid Thin Films with Modulable Surface and EnvironmentResponsive Behavior. Chem. Mater. 20, 4661-4668 (2008).

84. Lagergren, S. K. About the theory of so-called adsorption of soluble substances. Sven. Vetenskapsakad. Handingarl 24, 1-39 (1898).

85. Santhy, K. \& Selvapathy, P. Removal of reactive dyes from wastewater by adsorption on coir pith activated carbon. Bioresour. Technol. 97, 1329-1336 (2006).

86. Ho, Y. S. \& Mckay, G. The kinetics of sorption of basic dyes from aqueous solution by sphagnum moss peat. Can. J. Chem. 76, 822-827 (1998)

87. Bulut, E., Özacar, M. \& Şengil, İ. A. Adsorption of malachite green onto bentonite: Equilibrium and kinetic studies and process design. Micropor. Mesopor. Mat. 115, 234-246 (2008).

88. Zhao, D. et al. Facile preparation of amino functionalized graphene oxide decorated with $\mathrm{Fe}_{3} \mathrm{O}_{4}$ nanoparticles for the adsorption of Cr(VI). Appl SurfSci 384, 1-9 (2016).

89. Foo, K. Y. \& Hameed, B. H. Insights into the modeling of adsorption isotherm systems. Chem. Eng. J. 156, 2-10 (2010).

90. Elmorsi, T. M., Elsayed, M. H. \& Bakr, M. F. Enhancing the removal of methylene blue by modified ZnO nanoparticles: kinetics and equilibrium studies. Can. J. Chem. 95, 590-600 (2017).

91. Reed, B. E. \& Matsumoto, M. R. Modeling Cadmium Adsorption by Activated Carbon Using the Langmuir and Freundlich Isotherm Expressions. Sep. Sci. Technol. 28, 2179-2195 (1993).

92. Ayawei, N., Ebelegi, A. N. \& Wankasi, D. Modelling and Interpretation of Adsorption Isotherms. J. Chem, https://doi. org/10.1155/2017/3039817 (2017)

93. Peric, J., Trgo, M. \& Medvidovic, N. V. Removal of zinc, copper and lead by natural zeolite - a comparison of adsorption isotherms. Water Res. 38, 1893-1899 (2004).

94. Aranovich, G. L. \& Donohue, M. D. Vapor adsorption on microporous adsorbents. Carbon 38, 701-708 (2000)

95. Fan, S. S. et al. Facile synthesis of tea waste/ $\mathrm{Fe}_{3} \mathrm{O}_{4}$ nanoparticle composite for hexavalent chromium removal from aqueous solution. RSC Adv. 7, 7576-7590 (2017).

96. Khan, A. A. \& Singh, R. P. Adsorption Thermodynamics of carbofuran on $\mathrm{Sn}(\mathrm{Iv})$ arsenosilicate in $\mathrm{H}^{+}, \mathrm{Na}^{+}$and $\mathrm{Ca}^{2+}$-forms. Colloid Surf. 24, 33-42 (1987).

97. Liu, H., Zhang, F. \& Peng, Z. Y. Adsorption mechanism of Cr(VI) onto GO/PAMAMs composites. Sci. Rep. 9, 3663 (2019).

98. $\mathrm{Pu}, \mathrm{S}$. Y. et al. An efficient photocatalyst for fast reduction of $\mathrm{Cr}(\mathrm{VI})$ by ultra-trace silver enhanced titania in aqueous solution. Catalysts 8, 251 (2018)

99. Tan, J. S., Song, Y. H., Huang, X. H. \& Zhou, L. Facile functionalization of natural peach gum polysaccharide with multiple amine groups for highly efficient removal of toxic hexavalent chromium (Cr(VI)) ions from water. ACS Omega 3, 17309-17318 (2018).

100. Choi, K. et al. Chromium removal from aqueous solution by a PEI-silica nanocomposite. Sci. Rep. 8, 1438 (2018).

101. Park, D., Yun, Y. S. \& Park, J. M. Studies on hexavalent chromium biosorption by chemically-treated biomass of Ecklonia sp. Chemosphere 60, 1356-1364 (2005).

102. Mohan, D. \& Pittman, C. U. Activated carbons and low cost adsorbents for remediation of tri- and hexavalent chromium from water. J. Hazard. Mater. 137, 762-811 (2006).

\section{Acknowledgements}

This work was supported by the Basic Science Research Program through the National Research Foundation of Korea (NRF), funded by the Ministry of Education, Korea (NRF-2015R1D1A1A01059580 and NRF2019R1F1A1060060), by the Nano-Material Technology Development Program through the National Research Foundation of Korea (NRF) funded by the Ministry of Science, ICT and Future Planning (2009-0082580). This work was also supported by the Basic Core Technology Development Program for the Oceans and the Polar 
Regions of the National Research Foundation of Korea (NRF), funded by the Ministry of Science and ICT, Republic of Korea (NRF-2015M1A5A1037054).

\section{Author contributions}

E.-H.J. and S.C. designed research. E.-H.J. performed all experiments. E.-H.J. and S.C. analyzed data. S.C. and E.H.J. prepared all figures. E.-H.J., S.P.P., I.K., and S.C. wrote the paper. All authors revised, reviewed, and approved the manuscript.

\section{Competing interests}

The authors declare no competing interests.

\section{Additional information}

Supplementary information is available for this paper at https://doi.org/10.1038/s41598-020-61505-1.

Correspondence and requests for materials should be addressed to S.C.

Reprints and permissions information is available at www.nature.com/reprints.

Publisher's note Springer Nature remains neutral with regard to jurisdictional claims in published maps and institutional affiliations.

(c) (i) Open Access This article is licensed under a Creative Commons Attribution 4.0 International License, which permits use, sharing, adaptation, distribution and reproduction in any medium or format, as long as you give appropriate credit to the original author(s) and the source, provide a link to the Creative Commons license, and indicate if changes were made. The images or other third party material in this article are included in the article's Creative Commons license, unless indicated otherwise in a credit line to the material. If material is not included in the article's Creative Commons license and your intended use is not permitted by statutory regulation or exceeds the permitted use, you will need to obtain permission directly from the copyright holder. To view a copy of this license, visit http://creativecommons.org/licenses/by/4.0/.

(c) The Author(s) 2020 